\title{
Article
}

\section{The influence of children's reading ability on initial letter position encoding during a reading-like task}

Pagán, Ascensión, Blythe, Hazel I. and Liversedge, Simon Paul

Available at https://clok.uclan.ac.uk/35226/

Pagán, Ascensión, Blythe, Hazel I. and Liversedge, Simon Paul orcid iconORCID: 0000-0002-8579-8546 (2021) The influence of children's reading ability on initial letter position encoding during a reading-like task. Journal of Experimental Psychology: Learning, Memory and Cognition . ISSN 0278-7393

It is advisable to refer to the publisher's version if you intend to cite from the work. http://dx.doi.org/10.1037/xIm0000989

For more information about UCLan's research in this area go to http://www.uclan.ac.uk/researchgroups/ and search for <name of research Group>.

For information about Research generally at UCLan please go to http://www.uclan.ac.uk/research/

All outputs in CLoK are protected by Intellectual Property Rights law, including Copyright law. Copyright, IPR and Moral Rights for the works on this site are retained by the individual authors and/or other copyright owners. Terms and conditions for use of this material are defined in the policies page.

\section{CLoK}

Central Lancashire online Knowledge www.clok.uclan.ac.uk

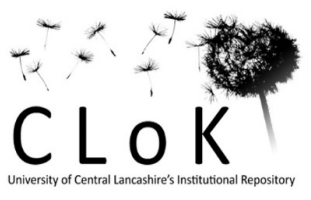


RUNNINGHEAD: children's reading ability and letter position encoding

The influence of children's reading ability on initial letter position encoding

during a reading-like task

Ascensión Pagán ${ }^{1}$, Hazel I. Blythe ${ }^{1} \&$ Simon P. Liversedge ${ }^{2}$

${ }^{1}$ Northumbria University, ${ }^{2}$ University of Central Lancashire

Author Note

Ascensión Pagán and Hazel I. Blythe, Department of Psychology, Faculty of Health and Life Science, Northumbria University, Newcastle upon Tyne, United Kingdom. Simon P. Liversedge, School of Psychology, University of Central Lancashire, Preston, United Kingdom.

Correspondence regarding this article should be addressed to Ascensión Pagán, Department of Psychology, Faculty of Health and Life Science, Northumbria University, Northumberland Building, Newcastle upon Tyne, NE1 8ST, United Kingdom. Email:ascension.pagan@northumbria.ac.uk 


\begin{abstract}
Previous studies exploring the cost of reading sentences with words that have two transposed letters in adults showed that initial letter transpositions caused the most disruption to reading, indicating the important role that initial-letters play in lexical identification (e.g., Rayner et al., 2006). Regarding children, it is not clear whether differences in reading ability would affect how they encode letter position information as they attempt to identify misspelled words in a reading-like task. The aim of this experiment was to explore how initial-letter position information is encoded by children compared to adults when reading misspelled words, containing transpositions, during a reading-like task. Four different conditions were used: control (words were correctly spelled), TL12 (letters in first and second positions were transposed), TL13 (letters in first and third positions were transposed) and TL23 (letters in second and third positions were transposed). Results showed that TL13 condition caused the most disruption, while TL23 caused the least disruption to reading of misspelled words. Whilst disruption for the TL13 condition was quite rapid in adults, the immediacy of disruption was less so for the TL23 and TL12 conditions. For children, effects of transposition also occurred quite rapidly but were longer lasting. The time course was particularly extended for the less skilled relative to the more skilled child readers. This pattern of effects suggests that both adults and children with higher, relative to lower, reading ability encode internal letter position information more flexibly to identify misspelled words, with transposed letters, during a reading-like task.
\end{abstract}

Keywords: letter position, children, reading ability, eye movements. 


\section{Introduction}

The aim of this study was to examine the influence of reading ability upon how easily adults and children can process misspelled words in sentences as they try to identify them during a reading-like task. Specifically, we compared adults and children on their ability to identify (and then read) words containing letter transpositions, as well as investigating whether children's reading ability influences how they encode orthography (letter position information) as they attempt to identify misspelled words.

\section{$\underline{\text { Reading ability }}$}

A large body of evidence has shown that the linguistic characteristics of the words impact eye movement behaviour during reading, demonstrating that there is a fundamental link between the reader's ease of cognitive processing and their consequent eye movement behaviour (e.g., Rayner, 2009; Liversedge \& Findlay, 2000). The vast majority of this work, however, comprises of data from skilled adult readers and, until recently, relatively little was known about children's eye movement behaviour during reading (see Blythe \& Joseph, 2011, for a review). More recently, interest in exploring how eye movement behaviour changes in relation to individual differences in reading ability has increased, and several studies have now shown that reading ability influences the nature and the time course of information used for lexical processing during sentence reading (Ashby, Rayner \& Clifton, 2005; Ashby, Yang, Evans \& Rayner, 2012; Chace, Rayner, and Well, 2005; Häikiö, Bertram, Hyönä \& Niemi, 2009; Haenggi \& Perfetti, 1994; Jared, Levy \& Rayner, 1999; Luke, Henderson, \& Ferreira, 2015; Veldre \& Andrews, 2014, 2015a, 2015b). These studies have shown that adult skilled readers have a larger perceptual span and exhibit greater parafoveal preview benefit than less skilled adult readers (Veldre \& Andrews, 2014, 2015a, 2015b). Similarly, during normal text reading, skilled adult readers showed shorter gaze durations and fewer refixations 
than less skilled adult readers (Luke et al., 2015), suggesting that skilled adult readers are faster to lexically process words than less skilled adult readers.

The Lexical Quality Hypothesis provides a theoretical framework for understanding how individual differences in lexical processing influence skilled reading in adults (Perfetti, 2007; Perfetti \& Hart, 2001; 2002). Perfetti and colleagues propose that there is a continuum on which a reader's cognitive lexical representations vary in terms of their quality, depending on the specification of information about a word's orthography (spelling), phonology (pronunciation) and semantic (meaning and grammatical class). A high quality lexical representation means that (1) all three types of information (orthography, phonology and semantics) are well specified in the reader's mental lexicon and (2) all three sources of information about the word are available at the same time during lexical processing, allowing for rapid and accurate lexical identification. In contrast, a low quality lexical representation means that at least one of these types of information is either under-specified or absent, resulting in longer times to lexically identify the word, or not being able to identify the word at all. When lexical processing occurs efficiently, attentional resources are allocated for those processes that occur at a higher level than lexical processing to understand the meaning of a sentence or text (e.g., syntactic and semantic integration). There is variability both within an individual's lexicon, with some words having higher quality representations than others, as well as between individuals, with more skilled readers typically having more high quality lexical representations than less skilled readers. Thus, the more high quality representations a reader has, the faster and more efficient lexical processing is. These differences, both within and between individuals, arise from the reader's reading and writing experience.

As mentioned earlier, there is a body of evidence on the influence of reading ability on word identification in adults, showing shorter reading times for skilled compared to less skilled adult readers (Luke et al., 2015; Veldre \& Andrews, 2014; 2015a, 2015b); those data 
have been interpreted to support the Lexical Quality Hypothesis. With respect to overall differences between adults and children, eye movement studies have consistently documented shorter reading times for adults compared to children (e.g., Blythe, 2014; Blythe et al., 2006, 2009, 2011; Häikiö et al., 2009, 2010; Huestegge et al., 2009; Joseph et al., 2009; Mancheva et al., 2015; McConkie et al., 1991; Pagán et al., 2016; Rayner, 1986; Reichle et al., 2013; Tiffin-Richards \& Schroeder, 2015; Zang et al., 2012). Such differences might also be explained by the Lexical Quality Hypothesis which states that, as a consequence of their greater proportion of high quality lexical representations, the rate of lexical processing should be faster in more skilled readers (Perfetti \& Hart, 2001; 2002).

Until now, however, there have been almost no studies exploring the influence of children's reading ability on eye movements in reading, or reading-like, tasks. One exception to this is the paper by Häikiö et al. (2009), who examined the letter identity span, the region around the point of fixation within which readers are able to encode the identity of the letters within words, whilst comparing more and less skilled Finnish adult and child $\left(2^{\text {nd }}, 4^{\text {th }}\right.$ and $6^{\text {th }}$ graders) readers. Consistent with an earlier study examining the perceptual span (Rayner, 1986), they found that the letter identity span was smaller in children than in adults -5 characters for $2^{\text {nd }}$ grade, 7 for $4^{\text {th }}$ grade, 9 for $6^{\text {th }}$ grade and adults. Häikiö et al. also found that more skilled child readers had shorter overall reading times as well as a larger letter identity span than less skilled child readers. This result demonstrates that, even within beginning readers, individual differences in reading ability affect orthographic encoding during lexical identification. Critically, this study also demonstrates that parafoveal preprocessing of letters within upcoming words in a sentence will be minimal in less skilled child readers (as their letter identity span may only include the currently fixated word). Therefore, given that parafoveal processing may be reduced in less skilled child readers, it is vital to use a paradigm that allows us to investigate whether individual differences in reading 
ability modulate foveal orthographic processing (letter position encoding) in children during a reading-like task.

In the present study, our aim was to conduct an eye movement experiment to investigate how children who differ in reading ability (but all of whom read appropriately for their age) encode orthographic information during direct fixation as they engage in a reading-like task. We examined adults' and children's reading of sentences in which all words over 5 letters long contained a misspelling, and readers were required to read these sentences as normally as possible. Reading in this paradigm was not natural or normal because the words that formed the sentences were disrupted (in fact, they were transposed letter nonwords). However, we used a paradigm in which foveal orthographic manipulations were employed through force of necessity, given the parafoveal processing limitations of less skilled readers.

\section{$\underline{\text { Reading misspelled words }}$}

There are many ways to manipulate orthography in order to generate misspelled words; here, we focus upon manipulating letter transpositions within words. This approach is wellestablished in the published literature on lexical identification (e.g., see Grainger, 2008; Frost, 2012, for reviews). In this way, researchers have sought to examine whether the identities and positions of letters within words are encoded independently or at the same time. Typically, misspelled words have been used to compare letter transpositions within words, where the identities of all the letters remain the same but the positions of two letters within a word are switched (e.g., unmber from number), to substitutions, where the identities of the same two letters are altered (e.g., acmber). Similarly, the inclusion of transposed letter misspelled words in sentences to examine lexical processing has demonstrated that skilled adult readers have some degree of flexibility in encoding the positions of letters within words as they read, such that there is a relatively small cost associated with reading transposed text 
(Rayner, White, Johnson, \& Liversedge, 2006; White, Johnson, Liversedge \& Rayner, 2008). As a consequence of this, and other evidence, new models of word identification have been developed to account for this flexible letter position encoding (the SOLAR model (Davis, 1999, 2010); the Open Bigram model (Grainger \& van Heuven, 2003; Grainger, Granier, Fariolli, van Assche \& van Heuven, 2006; Grainger \& Ziegler, 2011); the Overlap model (Gómez, Ratcliff \& Perea, 2008); the SERIOL model (Whitney, 2001), and Grainger and Ziegler's model (2011)). In this way, whilst reading misspelled words might not seem to be normal reading, manipulations such as letter transpositions allow for careful examination of how a misspelled word's orthographic similarity to its correctly spelled base word affects how easily it can actually be lexically identified. Indeed, such manipulations have been used to understand how efficiently skilled adult readers are able to access lexical representations based on imperfect orthographic input using isolated word recognition (e.g., Andrews \& Hersch, 2010; Andrews \& Lo, 2012; Perea \& Estévez, 2008) and sentence reading paradigms (Pagán, Blythe \& Liversedge, 2016; Tiffin-Richards \& Schroeder, 2015).

\section{Children's reading of misspelled words}

Regarding how the letters of a word are encoded by children, there have been some studies using isolated word paradigms (Acha \& Perea, 2008, Castles, Davis \& Forster, 2003; Castles, Davis \& Letcher, 1999; Castles, Davis, Cavalot \& Forster, 2007; Friedman, Dotan \& Rahamim, 2010; Grainger, Lété, Bertand, Dufau \& Ziegler, 2012; Kohnen \& Castles, 2013; Kohnen, Nickels, Castles, Friedman \& McArthur, 2012; Lété \& Fayol, 2013; Paterson, Read, McGowan \& Jordan, 2015; Perea \& Estévez, 2008; Ziegler, Bertand, Lété \& Grainger, 2014). Consistently, these studies have shown that 7-9 years old children encode letter position information flexibly, as is known to be the case for skilled adult readers. Flexibility in letter position encoding is obtained when there is a greater advantage for processing transposed letter nonwords (e.g., jugde) relative to substituted letter nonwords (e.g., junpe). In these 
studies, the difference between adults and children is in the magnitude and direction of the transposed letter effect. Some studies found that the magnitude of such advantage which was greater for 7-9 year old children compared to 10-11 year old children or adults (e.g., Acha \& Perea, 2008; Castles et al., 1999, 2007; Perea \& Estévez, 2008). This difference in the size of the effect has been interpreted as showing that lexical representations are less precisely specified in children than adults, and therefore, children are able to gain access to representations via less precise orthographic information. The lexical tuning hypothesis (Castles et al., 2007) suggests that beginning readers, who know a relatively small number of words, encode only approximate information about letter position (flexible letter position encoding), resulting in successful identification of a word even though there may not be full overlap between their cognitive representation of the word's orthography and the visual input string. As vocabulary size increases with age and reading ability, the lexical identification system is argued to become more precisely tuned in order to distinguish between orthographically similar words, resulting in a reduction in the magnitude of flexible letter position encoding.

In contrast, other studies have found that the size of the transposed letter effect increases with age, indicating that letter position encoding becomes more flexible with reading development (Grainger et al., 2012; Lété \& Fayol, 2013; Ziegler et al., 2014). This evidence is interpreted using the Multiple Route model (Grainger \& Ziegler, 2011). This model assumes that beginning readers will process letters within a word serially by phonological recoding. Later on, as the orthographic processing develops, letters are processed in parallel due to the development of position-specific letter detectors. Finally, this position specific detectors will cause the development of a coarse letter position information encoding as reading develops. 
All these studies, however, are based on the assumption that a greater difference between transposed letter words and substituted letter words for children results from relative ease of processing the transposed letter words compared to the adults. However, it is unclear from these studies what is driving these transposed letter effects. It may be the case that children find transposed letter words disproportionately easy to process, or substituted letter words disproportionately difficult to process, compared to adults. Without the inclusion of a control condition that is an exact match to the base word, which was unfortunately the case for most of these studies (Acha \& Perea, 2008; Castles et al., 2007; Ziegler et al., 2014; Grainger et al., 2012; Lété \& Fayol, 2013), it is not straightforward to distinguish between these two possibilities (see Kinoshita, Castles \& Davis, 2009). One study, however, has attempted to directly address this issue. Kezilas, McKague, Kohnen, Badcock and Castles (2017) investigated the development of letter position encoding using a masked priming lexical decision task in four different groups - children aged 7-9 years, 9-10 years, or 10-12 years old, and adults. They presented four different primes: the identity, a transposed letter nonword, a substituted letter nonword and an all different letter nonword. When comparing the transposed letter prime with the identity condition, they observed that the magnitude of the cost associated with letter transpositions varied across groups. In the raw means, the direction of this was not monotonic across ages; however, the data were transformed prior to analysis due to skewed RT distributions from the younger participant groups. Based on the transformed condition means, Kezilas et al. argued that the cost associated with TL relative to the identity primes increases with age. This finding is consistent with the lexical tuning hypothesis. Note that these findings come from the masked priming technique, which typically reflects pre-lexical processing of prime stimuli (e.g., Kinoshita et al., 2009). Participants would, therefore, be unlikely to be aware of the transposed letter nonwords 
primes. We wished to examine reader's processing of misspelled words using the more naturalistic silent sentence reading-like task.

With respect to sentence reading, or reading-like tasks, no studies to date have examined how children foveally process misspelled words when they directly fixate them, when they are embedded in meaningful sentence contexts. Note, though, that two studies have examined transposed letter effects during sentence reading in children relative to adults, but both used the boundary paradigm (Rayner, 1975), and so, the influence of misspellings was upon parafoveal pre-processing rather than foveal processing (Pagán, Blythe \& Liversedge, 2016; Tiffin-Richards \& Schroeder, 2015). Pagán et al., (2016) tested 8-9 years old child readers and investigated whether parafoveal pre-processing of letter identity and position information in a word's initial trigram were encoded as flexibly in children as in adults. Letter manipulations (transpositions or substitutions) were either in positions 1 and 2, 1 and 3, or 2 and 3, within each word. In terms of overall group differences, children had longer reading times than adults, consistent with the idea of a developmental increase in the rate of lexical processing (Perfetti \& Hart, 2001; 2002; Reichle, Liversedge, Drieghe, et al., 2013). In contrast, however, they found an equivalent advantage for transposed letter previews over substituted letter previews in both adults and children, such that the cost of processing for adjacent letters was reduced compared to non-adjacent letters. Indeed, adjacent transposed letter conditions showed similar fixation times to those for the identity. These effects suggest that both groups (adults and skilled child readers) were able to extract adjacent letter position information independently from letter identity information from the parafovea. Note that the parafoveal processing effects for the children in this study arose due to the fact that they were relatively skilled readers. The mean reading age of these children was 11.1 years $(\mathrm{SD}=2.4)$, showing that most of them were reading at a higher level than would be expected for their age (8-9 years old). On the basis of the eye movement data, it was suggested that 
orthographic processing in these children was similar to adults. Overall differences in reading times between adults and children must, therefore, be attributable to developmental changes in aspects of reading that occur subsequent to orthographic encoding. Transposed letter effects for German children in parafoveal preview were also reported by Tiffin-Richards and Schroeder (2015) ${ }^{\mathrm{i}}$

In summary, previous studies have demonstrated that: (1) individual differences in adults' reading ability influence the efficiency of lexical identification during silent sentence reading, although very little work has been done on this topic with beginning child readers; (2) encoding the positions of letters within words is flexible in both skilled child readers and adult readers; (3) the only evidence for flexible letter position encoding in children has come from isolated word recognition or the boundary paradigms (parafoveal processing during normal sentence reading). What is not known, to date, is the extent to which children's reading ability modulates the ease with which they can process misspelled words within sentences when they directly fixate those words.

In the present study, we explored whether children's reading ability influences the nature of orthographic encoding used for lexical identification as they read multiple misspelled words (created by letter transpositions) embedded in meaningful sentence contexts. In order to examine the influence of reading ability upon processing of misspelled words, it was vital to allow children (with no reading difficulties) to directly fixate those words, given the reduction in the perceptual span associated with lower reading ability (Häikiö et al., 2009; Rayner, 1986). Thus, here, both adults and children engaged in a reading-like task, processing sentences containing multiple words with letter transpositions that remained on the screen, unchanged, throughout the entire trial, as well as control sentences in which all words were correctly spelled. Note that presenting multiple, misspelled words within a sentence poses a significant challenge to lexical identification for children, especially those with low reading 
ability. In our view, this is an advantageous characteristic of the current paradigm, in that our manipulations maximize the possibility that the effects emerge, and therefore, allow us to examine the time course of both normal and disrupted orthographic encoding in relation to children's reading ability. Finally, within our manipulation of transposed letters, we also examined the influence of the positions of the specific letters that were transposed to produce the misspelled words in our reading-like task.

\section{Initial versus Internal Letters}

The importance of initial letter identity and position information has been demonstrated in skilled adult reading using a variety of manipulations such as letter degradation (e.g., Jordan, Thomas, Patching \& Scott-Brown, 2003) and letter transposition (e.g., Rayner et al., 2006; White et al., 2008; see also Wang et al., 2013; Yan et al., 2012 for evidence from stroke deletion manipulation in Chinese). These studies, where all the words in the sentences were manipulated, showed that the degradation or transposition of a word's initial letter caused a greater cost to reading (longer reading times) than internal letter degradation or transposition, indicating the elevated status of word-initial letters for lexical identification during sentence reading. These studies support the idea that internal letter position information is encoded more flexibly than initial letter information due to the importance of the word initial letter as a lexical access unit for word identification (see Briihl \& Inhoff, 1995; Gagl, Hawelka, Richlan, Schuster \& Hutzler, 2014; Jonhson, 2007; Johnson \& Dunne, 2012; Johnson \& Eisler, 2012; Johnson, Perea \& Rayner, 2007; Jordan et al., 2003; Pagán et al., 2016; Plummer \& Rayner, 2012; Rayner, McConkie \& Zola, 1980; Tiffin-Richards \& Schroeder, 2015). This evidence is consistent with new models of letter position encoding (the SOLAR model, Davis, 1999, 2010; the Open Bigram model, Grainger \& van Heuven, 2003; Grainger et al., 2006; Grainger \& Ziegler, 2011; the Overlap model, Gómez et al., 2008; and the SERIOL model, Whitney, 2001), which account for flexible letter position encoding. They 
predict different mechanisms to encode letter position information for internal and initial letters. They assume that internal letter position information is encoded independently from letter identity information, using a flexible letter position encoding mechanism. In contrast, initial letter position information is encoded jointly with letter identity information, using a strict letter position encoding mechanism.

Although some studies have been carried out to explore the role of initial versus internal letter encoding in children during parafoveal pre-processing (Pagán et al., 2016; TiffinRichards \& Schroeder, 2015), these studies did not investigate the role of reading ability. Rayner and Kaiser $(1975)$ recruited $6^{\text {th }}$ grade readers who were very good readers, and $12^{\text {th }}$ grade readers who were poor readers (they read at a similar level to children in the $4^{\text {th }}$ grade), for a reading aloud task. They found that texts with initial, visually dissimilar substituted letters (e.g., yorld) had a greater cost to reading than texts with middle or final dissimilar substituted letters (e.g., wogld or worlr) for both groups of children, indicating that initial letters are also very important for lexical identification (as per Pagán et al., 2016). Although poor readers took more time than good readers to identify the words overall, the contrast between internal and external letter transposition effects was the same for both groups of children.

In the present study, we were also interested in how children, as well as adults, read sentences containing words with misspellings. In the present experiment, however, we did not require readers to read aloud, and misspellings were always formed through the transposition of two letters. We used a reading-like task, in which participants read sentences containing a target word that was manipulated across four different experimental conditions: control (correctly spelled words); letters $1 \& 2$ transposed (TL12); letters $1 \& 3$ transposed (TL13); and letters $2 \& 3$ transposed (TL23). Note that we applied the letter transposition manipulation to all words in the sentences longer than five letters in order to reduce the 
saliency of the target words (see White \& Liversedge, 2004; 2006). We provide our basic predictions for the main experimental manipulations as follows. First, we were able to examine differences between adults and children in relation to normal reading, given that we included a condition in our experiment in which all the words of the sentence were correctly spelled. Thus, on the basis of the Lexical Quality Hypothesis and consistent with the published literature, we predicted longer reading times overall in children relative to adults (see Blythe \& Joseph, 2011 for a review), and for less skilled compared to skilled child readers (Häikiö et al., 2009; see also Luke et al., 2015; Veldre \& Andrews, 2014; 2015a; 2015b). Second, as per Häikiö et al. (2009), we predicted that fixations and reading time measures would be shorter for more skilled child readers than less skilled child readers, and we predicted that such effects would hold both when children read sentences with and without misspelled words. Third, with respect to the adults' reading times in the misspelled word conditions, we predicted that: (a) reading times would be shorter for sentences without misspellings than for sentences with misspellings (e.g. Rayner et al., 2006; White et al., 2008); and (b) on average, the cost associated with reading misspelled words would be greatest in the TL13 condition, slightly less in the TL12 condition, and least in the TL23 condition (Pagán et al., 2016).

With respect to differences between adults' and children's reading times on misspelled words, although we predicted qualitatively similar patterns of results for adults and children overall (TL13 > TL12 > TL23), both the time course and the magnitude of the effect we predicted to differ between the two groups. For time course, we predicted that the effect of misspellings against the control condition would occur in later measures for children compared to adults (Perfetti \& Hart, 2002). For magnitude, there were two possible, opposite patterns. First, if the multiple-route model is correct, (Grainger \& Ziegler, 2011), then the cost of processing transposed letter misspelled words should be smaller for adults than 
children because they have more precise lexical representations and, therefore, less disruption when the overlap between the input and the stored representation is partial. Alternatively, if the lexical tuning hypothesis is correct (Castles et al., 2007), then the opposite pattern of effects should be observed; namely, the cost of processing transposed letter misspelled words should be larger for adults compared to children (as per Kezilas et al., 2017).

Within the child sample, we also predicted that reading ability would modulate the effects of misspellings on reading times. Specifically, we predicted that the more skilled child readers will show a more adult-like pattern in their reading times on misspelled nonwords, and a smaller cost from processing nonwords with internal compared to initial letter transpositions, when compared to less skilled child readers.

Finally, assuming that all participants do, ultimately, detect misspellings and are able to correctly identify words based on misspelled forms, then we would expect their comprehension accuracy for the sentences to be quite high indicating that they understood the sentences.

\section{Method}

\section{Participants}

A total of 72 participants ( 24 adults and 48 children) took part in this experiment. The children were recruited from Years 3 and 4 of primary schools in and near Southampton and had a mean age of 9 years (range $=7.11-9.9, S D=0.6)$. The adult participants were from the University of Southampton and had a mean age of 20 years (range $=18-27, \mathrm{SD}=2.0$ ). All participants had normal or corrected to normal vision and were native speakers of English with no known reading difficulties.

Word reading, pseudoword decoding and reading comprehension for each participant were assessed using the Wechsler Individual Achievement Test II (WIAT-II; Wechsler, 
2005) to make sure that they did not have any reading difficulties. Standardized scores were calculated using the norming tables provided for the appropriate age group (for children aged 4 to 16 years 11 months in the UK, and for the adults, the scoring supplement for 17-85 years from the U.S). Results confirmed that no participants showed evidence of reading difficulties (see Table 1). All participants were unaware of the purpose of the experiment until afterwards. University students received course credits as a reward for participating. This study was approved by the University of Southampton's Research Ethics Committee.

Insert Table 1 about here

\section{Apparatus}

The sentences were presented on a 21 " CRT monitor, with a refresh rate of $100 \mathrm{~Hz}$ and a resolution of $1024 \times 768$, interfaced with a PC at a viewing distance of $60 \mathrm{~cm}$. Sentences were presented in black, Courier New, size 12 font on a grey background; three characters subtended $1^{\circ}$ of visual angle. Although reading was binocular, eye movements were recorded only from the right eye, using an EyeLink 1000 tracker (S.R. Research Ltd.), with forehead and chin rests in order to minimize head movements. The spatial resolution of the eyetracker was $0.05^{\circ}$, and the sampling rate was $2000 \mathrm{~Hz}$.

\section{Material and design}

Fifty-six experimental sentences containing a 6-7 letter target word were selected. Target words (nouns or adjectives) were bisyllabic with a CVC structure for the initial trigram, which was within the same syllabic unit (e.g., bandage). These target words had fewer than three orthographic neighbours and had a mean Age of Acquisition of 6.78 years $(S D=1.70)$ (Kuperman, Stadthagen-Gonzalez \& Brysbaert, 2012). Target word frequency was in a range between three and 276 per million using child frequency counts $(M=37, S D=$ 
53) (Children's Printed Word Database; Masterson, Dixon \& Stuart, 2003) and in a range between 0.61 and 3483 per million using adult frequency counts $(M=179, S D=559)$ (English Lexicon Project Database; HAL corpus, Balota l.l., 2007).

Four different conditions were generated for each target word. A control condition, in which the target word was spelled correctly (e.g., bandage), a nonword with the first and the second letters transposed (TL12, e.g., abndage), a nonword with the first and the third letters transposed (TL13, e.g., nabdage), and a nonword with the second and the third letters transposed (TL23, e.g., bnadage). None of the target transpositions produced real words, and all of the transpositions produced a change in spelling. As can been seen in the Appendix, transposing or substituting letters in position 13 created regular trigrams (e.g., pactaingastain from captain; note that all initial trigrams had a CVC structure), while the equivalent manipulations in positions 12 and 23 (e.g., acptain- imptain; cpatain-cgotain, respectively) were orthographically illegal (and resulted in a change to the CVC structure from the base word). Accordingly, there was a consistent influence upon pronounceability of the nonwords: 18/56 TL12 transpositions, 56/56 TL13, and 0/56 TL23 transpositions created pronounceable nonwords. In addition, for each sentence, all words which had five or more letters were manipulated by transposing the letters according to each condition, in order to reduce the salience of the target word within the sentence (e.g., Control: "The nurse had to put a fresh bandage on his leg after three weeks"; TL12:“The unrse had to put a fresh abndage on his leg faterh tree eweks"; TL13: "The runse had to put a erfsh nabdage on his leg tfaer rhtee eewks"; and TL23: "The nruse had to put a fersh bnadage on his leg atfer trhee weeks").

In addition, we created two types of questions. First, Yes/No comprehension questions were included after half of the experimental sentences to ensure that participants were able to ascertain the correct identity of the misspelled words based on their incorrect orthographic forms, and therefore construct a correct and meaningful interpretation of the 
sentence. Second, target word questions were included after a different $25 \%$ of sentences, to ensure that readers were able to ascertain the correct identity of the misspelled target word. For this second type of question, we created 54 pairs of words matched for length: each pair was comprised of the correct target word that had appeared in the sentence, and a distractor word (e.g., bandage and baggage). The distractor word was created from the correct word by changing between one and four letters. This resulted in two pairs with one letter different, 30 pairs with two letters different, 19 pairs with three letters different and three pairs with four letters different. The pair of words was presented in the centre of the screen and the participants had to indicate which of the two words had appeared (albeit in a misspelled format) in the sentence that they had just read.

To confirm that our experimental sentences could be understood by children in our selected age range (especially when misspelled words were manipulated), as well as to ensure that our sentences were more generally age-appropriate, we undertook a pre-screening procedure. We created four counterbalanced lists, using a Latin-square design, to ensure that every sentence was presented in each of the four different conditions, but no participant saw any single sentence repeated. Within each list, there were 14 correctly spelled sentences, 14 sentences containing a TL12 manipulation, 14 sentences containing a TL23 manipulation, and 14 sentences containing a TL13 manipulation. We asked 28 children (Year $3 \&$ 4: 7-9 years old) to rate our sentences on a scale of 1 (easy to understand) to 7 (difficult to understand), with seven children rating each list of sentences. We ran t-test comparisons in order to examine whether there was any difficulty in understanding the sentences as a function of the misspelled conditions (note that we did not time the children on this task; the children were simply tasked with rating their comprehension of the sentences and not the difficulty of identifying the words within that sentence). The results showed that there were no significant differences in comprehension between the four conditions $(t>0.3)$. Children 
found it relatively easy $(\mathrm{M}=2.3, \mathrm{SD}=0.9)$ to understand our experimental sentences. None of the children in this pre-screening study took part in the main eye tracking experiment.

After this pre-screening, the four counterbalanced lists were presented within the eye tracking experiment. Each list was read by 18 participants (six adults, twelve children), and included 4 practice sentences, and 56 experimental sentences (14 per condition). The sentences occupied one line on the screen (maximum $=60$ characters; $M=58$ characters), and the target nonword always appeared in the middle of the sentence. The experimental sentences were presented in a random order to each participant.

\section{Procedure}

The three reading subtests - word reading, pseudoword decoding and comprehensionof the WIAT-II were completed first, to confirm that our participants had no reading difficulties, then, the eye movement experiment was conducted. Participants were told that some of the letters in some of the words could be mixed up and, that he/she should be able to determine the meaning of those words. Thus, they should focus on reading each sentence for comprehension. After each sentence, the participant had to press a button on the game controller to continue and, following $50 \%$ of the sentences, to answer Yes/No to comprehension questions. In addition, following a different $25 \%$ of the sentences, the participant had to answer a two-choice question to demonstrate that they had correctly ascertained the identity of the misspelled target word. Participants were free to take a break whenever they wished and could withdraw from the experiment at any point. The experiment lasted about 50 minutes.

\section{Data analysis}

Participants who scored less than $65 \%$ on either the comprehension or the target word questions were removed from the analyses (a total of six child participants were removed). 
The "clean" function in DataViewer (SR Research) was used to trim the data.

Fixations shorter than $80 \mathrm{~ms}$, and which were located within one character space of the next or previous fixation, were merged into that nearby fixation; the rest of the fixations that were shorter than $80 \mathrm{~ms}$ and over $1200 \mathrm{~ms}$ were deleted. The final dataset was comprised of 924 fixations for the global analyses (the correctly spelled condition only) and 3629 fixations for the local analyses (including all four experimental conditions). In addition, fixations more than 2.5 standard deviations from each participant per condition's mean were removed (less that $3 \%$ ). The data were log transformed for analyses to reduce distribution skewing (Baayen, Davidson \& Bates, 2008).

A range of standard eye movement measures was computed for global and local analyses (Rayner, 2009). For global analyses, mean fixation duration (the mean duration of all fixations in the sentence), mean progressive saccade amplitude, mean sentence reading time, and the mean total number of fixations per sentence were included. For local analyses of the target word, single fixation duration (the time for which a word was fixated when it received only one first pass fixation), first fixation duration (the duration of the initial, firstpass fixation on a word, regardless of how many fixations it received), gaze duration (the sum of all consecutive fixations on a word before leaving the word), total fixation duration (the mean duration of all fixations on a word) and the total number of fixations on a word during first pass were included. The results for all local dependent measures are reported in full in Table 4; for brevity's sake, we only describe first fixation duration, gaze duration, and total fixation duration in the Results section.

Data were analysed by means of linear mixed effects (lme) modelling using the lmer function from the lme4 package (Bates, Maechler \& Bolker, 2012) within R (R Development Core Team, 2013). Two different lme models were constructed. The first lme model was run to investigate the effect of letter position information encoding in adults compared to 
children. For this, Group (Adults vs. Children) and Type (Control vs. TL12 vs. TL13 vs. TL23) variables were specified as fixed factors. The second lme model was run to examine whether letter position information encoding was modulated by reading ability in the child sample only. For this, Type (Control vs. TL12 vs. TL13 vs. TL23) and Reading Ability (as a continuous variable) were specified as fixed factors. For both lme models, we initially specified a full random structure for subjects and items, to avoid being anti-conservative (Barr, Levy, Scheepers \& Tily, 2013); however, these models failed to converge. We then trimmed the random structure of the model down until it converged. In the final model, in all cases, both participants and items were specified as random factors. Significance values and standard errors reflect, therefore, both participant and item variability (Baayen et al., 2008). Type and Group variables were categorical, while Reading Ability was a continuous variable (the standardized composite score from the WIAT-II). The reading ability was centered using "scale" (package STATS). We used "contr.sdif" (package MASS) to specify the two categorical factors (Group and Type). Following standard conventions, effects were considered significant when $t>2$. Finally, additional planned contrasts were carried out to compare the control and TL13 conditions; control and TL23 conditions; and TL12 and TL23 conditions for all dependent measures on the target word/nonword. For this, we created a contrast matrix to run the three specific contrasts at the same time within the models described above.

\section{Results}

The 24 adult participants scored a mean of $97 \%(\mathrm{SD}=4.4)$ on the comprehension questions and all of them scored $100 \%$ in the target questions. The 42 child participants scored an average of $83 \%(\mathrm{SD}=8.9)$ on the comprehension questions and an average of $97 \%$ $(\mathrm{SD}=5.8)$ in the target questions. The two groups of participants differed significantly in comprehension $(p s<0.00)$ and target accuracy $(p<0.01)$. For the comprehension questions, 
there were no differences across conditions in either adult (Control: M: 98\%, SD: 13\%;

TL12: $\mathrm{M}=98 \%, \mathrm{SD}=12 \% ; \mathrm{TL} 13: \mathrm{M}=98 \%, \mathrm{SD}=12 \% ; \mathrm{TL} 23: 99 \% ; \mathrm{SD}=12 \%)$ or child

(Control: M: 91\%, SD: 29\%; TL12: $\mathrm{M}=90 \%, \mathrm{SD}=29 \%$; TL13: $\mathrm{M}=92 \%, \mathrm{SD}=28 \%$; TL23: 92\%; $\mathrm{SD}=27 \%$ ) participants (all $p \mathrm{~s}>0.1$ ). It is clear that both the children and the adults were able to ascertain the identity of the target words based on their misspelled forms. As expected, comprehension rates were reduced for children relative to adults, though for both groups comprehension rates were high.

\section{Global analyses}

Global analyses were carried out to examine differences between the two groups of participants in their eye movement behaviour. Note that the transposed letter manipulation was well controlled for the target word/nonword, but not for the other words that were manipulated in the sentence (all those words containing five or more letters; to reiterate, this was done to reduce the saliency of the target word within the sentence). Thus, we did not explore transposition effects in these global analyses, but instead examined overall group differences using data from the control condition only (all words correctly spelled).

Adults had shorter fixation durations $(b=0.29, S E=0.03, t=9.0)$, longer progressive saccade amplitudes $(b=-0.41, S E=0.11, t=3.7)$, shorter sentence reading times $(b=0.60$, $S E=0.05, t=11.2)$, and made fewer fixations on the sentences than child readers $(b=7.4$, $S E=0.9, t=8.3$ ) (see Table 2 for means and standard deviations). These findings are consistent with previous studies investigating children's eye movement behaviour during normal silent sentence reading (Blythe, 2014; Blythe et al., 2006; 2009; 2011; Häikiö et al., 2009; Häikiö et al., 2009; 2010; Huestegge et al., 2009; Joseph et al., 2009; McConkie et al., 1991; Pagán et al., 2016; Rayner, 1986; Tiffin-Richards \& Schroeder, 2015). 
In addition, within the child sample, we found that reading ability modulated both mean fixation duration $(b=-0.00, S E=0.00, t=2.8)$ and total sentence reading time $(b=$ $0.60, S E=0.05, t=11.2$ ), such that children with higher scores in reading ability made shorter fixations and spent less time reading sentences than children with lower scores in reading ability (see Figure 1). There was, however, no effect of reading ability in either mean saccade amplitude or fixation count $(t \mathrm{~s}<1.2)$ (see Table 2 for means and standard deviations).

Insert Figure 1 and 2 about here

\section{Local analyses}

Overall differences between adults and children

Consistent with the global analyses, the lme model showed that the comparisons between adult and child readers were significant for all dependent measures (see Table 3 for coefficients, standard errors and t-values). Specifically, adults had shorter viewing times on the target words/nonwords than children (see Table 4 for means and standard deviations and Figure 2).

Insert Tables 3 and 4 about here

The cost of processing misspelled words in adults and children

In first fixation duration, there were four key results. First, there were overall differences between the TL12 and TL13 conditions, but not the TL23 condition, relative to the control condition. Second, the TL12 and TL13 effects also showed a significant interaction with participant group. The cost associated with these misspellings that transposed the first letter of the word, relative to correctly spelled words, was proportionally greater for adults than for children. Third, within the misspelled word manipulations, the cost was largest 
for the TL13 condition, as shown by comparisons against both the TL23 condition and the TL12 condition (though the latter effect was only marginally significant here). Fourth, this greater cost of the TL13 condition was only significant for adults.

In gaze duration, the adults' data patterned very similarly to those from first fixation duration. One change was that, in gaze duration, the cost of processing TL12 nonwords increased in magnitude such that the comparison against the TL23 condition also became significant (note that the TL23 nonwords received first fixation durations and gaze durations that were not significantly longer than control words). Interestingly, there was a difference in the interaction terms with participant group that reflected the children's data beginning to pattern more similarly to the adults' data. In gaze duration, the cost associated with TL12 nonwords was proportionally similar for both adults and children (where in first fixation duration children had showed less of a cost). For the TL13 nonwords, both groups showed a cost relative to control words in both first fixation duration and gaze duration; the magnitude of this was greater in adults than children.

Finally, in total fixation duration, the TL13 condition resulted in the greatest cost to processing for both groups (though the magnitude of this was proportionally greater for adults). In total fixation duration, for the first time, the TL23 condition did result in longer reading times than the control condition (suggesting that participants were, upon re-reading, able to detect this misspelling). Interestingly, a significant interaction showed that this TL23 cost was proportionally greater for children than for adults.

It is important to note that the means in Table 3 are calculated from the raw data. Inspection of these means indicates that the transposed letter conditions were more costly for children than for adults. For example, the TL12 manipulation increased adults' gaze duration by $109 \mathrm{~ms}$ from the control condition mean, but it increased children's gaze duration by 
$251 \mathrm{~ms}$. It is, however, critical to consider these relative differences between conditions in proportion to the absolute baseline provided by the control condition. In this example, children's mean gaze duration in the correctly spelled condition was $538 \mathrm{~ms}$, compared to $249 \mathrm{~ms}$ for the adults. Thus, although the means for the TL12 condition indicate that children experienced more disruption than adults from this manipulation, the proportional increase for each condition was very similar across the two groups - children's gaze durations increased by $47 \%$ and adults' gaze durations by $44 \%$. For this reason, the lower half of Table 3 includes the proportional cost for the TL conditions for each group separately. These calculations support our LME analyses in showing that, where there were group differences in the magnitude of the effect, it was typically larger in the adult data.

In summary, as can be seen in Figure 2, both adults and children were sensitive to misspelled words in very early measures of processing (first fixation duration). The groups differed, however, in the time course over which the specific TL manipulations had differential costs to processing. As early as first fixation duration, adults showed a proportionally greater cost to processing when (a) the first letter of the word was manipulated and (b) the manipulated letters were not adjacent within the word. These patterns between TL conditions emerged in children in the later measures of gaze duration and total fixation duration.

Reading ability effects on letter position encoding in children

As mentioned in the Methods section, reading ability was included in our analysis as a continuous variable. From our pen-and-paper assessment task (WIAT-II), we used the standardized composite score within our child sample only. The reading ability variable was centered using "scale" (package STATS) and we used "contr.sdif" (package MASS) to specify the two fixed factors (Reading ability and Type of nonword) in our lme model (see Table 5). 
The main effect of reading ability was reliable in single fixation and go past durations such that children with higher reading ability spent less time processing the target and rereading previous portion of the text than children with reduced reading ability. At a basic level, this finding is consistent with our hypothesis that reading times will be modulated by reading ability.

The interactions between reading ability and the type of nonword were not reliable in single or first fixation $(t \mathrm{~s}<1.9)$. In contrast, there were significant interactions between reading ability and the type of nonword in gaze duration, go past time and total time. Recall that, across the entire sample of children, correctly spelled words received the shortest reading times, with a slight increase for internal and adjacent letter transpositions (TL23). There was a larger cost for transpositions involving the first letter of the word (TL12), and this was particularly marked for transpositions that moved the first letter of the word to a nonadjacent position (TL13). In children, this pattern of effects began to emerge in gaze duration, and was robust in total fixation duration. More specifically, reading ability influenced go past and total times on TL12 ( $\mathrm{t} s>2.91$ ) and TL13 ( $\mathrm{t} s>4.34$ ), modulating the magnitude of the effect such that the cost associated with both TL12 and TL13 nonwords increased with reading ability relative to both the control and the TL23 condition (see Figure 3). Clearly, more skilled child readers were patterning more similarly to the adults in terms of showing a greater cost associated with the letter transpositions.

Insert Figure 3 about here

To reiterate, the qualitative pattern of differences between nonword conditions was extremely consistent across adults and children, as well as across the range of reading abilities within our sample of children. Whilst adults and children primarily differed in terms 
of the time course over which these effects emerged, reading ability affected the magnitude of these effects within the sample of children. This pattern suggests that children with higher reading ability are able to encode internal letter position information more flexibly and are more sensitive to initial letters misspellings than children with reduced reading ability during a reading like-task.

\section{Discussion}

We conducted an experiment to examine how adults and children process misspelled words (transposed letter nonwords) in sentences as they attempt to identify them during a reading-like task. Furthermore, we examined the time course of both normal and disrupted orthographic encoding in relation to children's reading ability. To summarise our results, adults had shorter viewing times on the target word/nonword than children. With respect to the experimental manipulations, the correctly spelled word condition had the shortest viewing times in all dependent variables in children; in adults, the correctly spelled word condition had similar viewing times as the internal letter transposition condition (TL23) at early stages of processing. This pattern suggests that adults misperceived misspelled words containing an internal transposition and initially processed them as their base words during lexical processing. Children showed a cost to reading misspelled words regardless of the location of the letters that were transposed. Regarding the effect of the position of the letter transposition, whilst the pattern of effects was similar for adults and children, the time course of the effects was somewhat different. First, concerning the overall pattern of differences, the most disruption to reading was for misspelled words in the TL13 condition, slightly less in the TL12 condition, and least in the TL23 condition. Second, concerning the time course of this disruption, the effects emerged in very early measures for adults (first fixation duration) but in slightly later measures for children (gaze duration and total fixation duration). Finally, with respect to variability in reading ability within the children, this primarily affected the 
magnitude of the differences between conditions in total fixation durations, with a greater cost to processing as well as an increased sensitivity to initial orthographic disruption in words being associated with a higher level of reading ability.

\section{Overall developmental differences in reading}

As predicted, we found that overall, adults had shorter fixation durations and sentence reading times, and made longer saccades and fewer fixations during sentence reading than children. Furthermore, we found that adults had shorter reading times on the target words/nonwords than children. Together, these findings indicate that adults were able to identify the correct lexical entry for the target words/nonwords faster than children. This is consistent with previous studies that showed that lexical processing is slower in children compared to adults (e.g., Blythe, 2014; Blythe et al., 2006, 2009, 2011; Häikiö et al., 2009, 2010; Huestegge et al., 2009; Joseph et al., 2009; Mancheva et al., 2015; McConkie et al., 1991; Rayner, 1986; Reichle et al., 2013; Tiffin-Richards \& Schroeder, 2015; Zang et al., 2012). This finding is also consistent with the Lexical Quality Hypothesis (Perfetti \& Hart, 2001, 2002).

\section{The cost of processing misspelled words}

As expected, we observed that lexical identification was faster for correctly spelled words compared to misspelled words, suggesting that it is easier to identify a word whose orthographic information fully overlaps with its stored lexical representation than when this overlap is partial. In particular, there was a greater cost of processing misspelled words that had the first letter transposed, suggesting that altering word initial letters is particularly disruptive to lexical processing (Rayner et al., 2006; White et al., 2008). One condition in particular, TL13, resulted in substantial disruption to overall processing - total fixation durations on these misspelled words was increased by $654 \mathrm{~ms}$ for adults, relative to correctly 
spelled words. Three factors would have contributed to this disruption, all of which have been previously documented to cause disruption to lexical processing: (1) the first letter of the word was manipulated (e.g., Briihl \& Inhoff, 1995; Gagl et al., 2014; Jordan et al., 2003; Plummer \& Rayner, 2012; Rayner et al., 1980; Tiffin-Richards \& Schroeder, 2015); (2) the transposition manipulated non-adjacent letters (e.g., Blythe et al., 2014; Johnson, 2007; Johnson et al., 2007; Perea et al., 2008; Pagán et al., 2016); and (3) given the CVC structure of the initial trigrams within our target words, the TL13 manipulation maintained that structure by transposing two consonants, typically resulted in an orthographically and phonologically regular trigram, where the TL12 and TL23 conditions did not (see Appendix 1; Pagán et al., 2016). It is, perhaps, unsurprising, that nonwords in the TL13 condition received such long reading times, due to a triad of influences.

In contrast, and again consistent with previously published research, we found that misspelled words with adjacent, internal letter transpositions (the TL23 condition) resulted in similar reading times to the correctly spelled words at early stages of processing (Pagán et al., 2016; Perea, \& Lupker, 2003, 2004; 2007). This indicates that, early in processing, misspelled words with internal letter transpositions activated their base word's representation in the mental lexicon in a similar way to the correctly spelled words. This result suggests flexible letter position encoding for internal letters of a word in a reading-like task (e.g., Pagán et al., 2016), and is consistent with models of letter position encoding such as the SOLAR (Davis, 1999, 2010); the Open Bigram (Grainger \& van Heuven, 2003; Grainger et al., 2006; Grainger \& Ziegler, 2011), the Overlap (Gómez et al., 2008) and the SERIOL (Whitney, 2001) models. These models assume strict letter position encoding for initial letters and flexible letter position encoding for internal letters, due to initial letters playing an important role as lexical access units for word identification. Clearly, the present results are consistent with models of word identification that are based on these assumptions and suggest 
that even in a reading-like task such as the present paradigm, normal lexical processes are engaged at least to some extent. Later in processing, presumably after lexical identification had occurred (based on erroneously activating the representation of the correctly spelled word), even the TL23 nonwords resulted in longer total fixation durations compared to the control condition. Thus, eventually participants did detect the misspellings, but it appears that this only occurred at a later stage, when they were likely checking that their interpretation of the sentence was reasonable.

We were also interested to explore whether the cost associated with processing misspelled words was similar in adults and children. As expected, the overall pattern was similar for both groups of participants. Of particular interest was the magnitude of the cost associated with processing transposed letter nonwords. Recall that, due to different experimental methods (e.g., isolated word recognition vs. sentence reading) and designs (e.g., whether or not a correctly spelled baseline condition was included), it was not clear whether the cost associated with letter transpositions for children would be of greater magnitude (as per the Multiple Route Model; Grainger \& Ziegler, 2011) or lesser magnitude (as per the lexical tuning hypothesis; Castles et al., 2007) compared to adults. Kezilas et al. (2017) reported that the processing cost for letter transpositions increased with age, and linked this to the lexical tuning hypothesis. Here, during a reading-like task, we observed that the magnitude of the processing cost increased over time, with the greatest disruption observed for both groups in total fixation duration. We calculated the cost associated with each of the transposed letter conditions as a proportion of the two groups' baseline reading times in the correctly spelled control condition. These data, consistent with our LME models, indicate that the greater cost associated with processing transposed letter nonwords was with adults. This supports the lexical tuning hypothesis, which suggests that lexical representations are less precisely encoded in children than in adults (e.g., Castles et al., 2007). 
Despite the overall cost associated with letter transpositions being greater in children than adults, we also noted that the effects occurred more quickly in adults. The different time course between the two groups may be accounted for by the Lexical Quality Hypothesis (though note that this theory does not make any direct predictions about transposed letters per se; Perfetti, 2007; Perfetti \& Hart, 2002). Perfetti and Hart (2001; 2002) have shown that, for skilled readers with high quality lexical representations, partial information can activate lexical entries, and the specificity of those lexical representations allows the reader to discriminate between competing items rapidly. For example, in the case of homophones such as ROWS and ROSE, both lexical representations are activated from a presentation of one of the two orthographic forms but a skilled reader quickly discriminates between the two and identifies the correct lexical representation. The lexical quality predicts that where temporary confusion arises about the identity of a printed word, due to partial overlap with multiple lexical entries, then processing difficulty should be observed earlier for more skilled readers and a relative delay should be observed for less skilled readers. In the case of misspelled words such as letter transpositions, there are not two lexical representations that are competing for activation on the basis of overlapping input. Rather, we infer that when misspelled words are presented in foveal vision, skilled readers might also be able to access candidate lexical representations on the basis of partial orthographic overlap more quickly than less skilled readers.

\section{Children's reading ability on letter position encoding}

First, we predicted that children's reading ability would modulate reading times in both normal and disrupted orthographic encoding in our reading-like task. Consistently, the results showed that, overall, children with higher reading ability made shorter fixations and spent less time reading sentences than children with lower reading ability as they read correctly spelled words in sentences. We also found that reading ability within the children modulated the effect 
of letter transpositions, with more skilled child readers patterning more like adults. Specifically, children with higher reading ability spent less time on target words/nonwords than children with lower reading ability when they made a single fixation for lexical processing. This evidence is consistent with the idea that children with higher reading ability behave in a more adult-like manner, suggesting that their lexical processing is more efficient than children with lower reading ability.

Second, with respect to the letter position manipulation, the results showed that children with higher reading ability made shorter fixations on correctly spelled words relative to when the first letter was involved in a transposition (TL12 and TL13). Similarly, children with higher reading ability had shorter reading times when internal letters of a word were transposed (TL23) compared to when a word initial letter was transposed (TL12 and TL13). The magnitude of these differences between conditions was reduced in children with lower reading ability (see Figure 3). Again, this is consistent with the lexical tuning hypothesis (Castles et al., 2007).

In summary, the present study provides novel findings about how letter position information is encoded during a reading like-task. We used sentences with multiple misspelled words to evaluate word identification processes in adults and children of differing reading abilities. There were five key findings. First, consistent with previous studies, non-adjacent transpositions that manipulated the first letter of the word caused the most disruption to reading, whilst adjacent transpositions that only manipulated internal letters had a minimal cost to processing. Second, this qualitative pattern of effects was consistent across both adults and children. Third, the magnitude of these effects was proportionally greater in adults than in children, consistent with previously published studies and supporting the Lexical Tuning Hypothesis. Fourth, these effects occurred in earlier measures of processing for adults compared to children, suggesting delayed processing in children, and consistent with the 
Lexical Quality Hypothesis. Fifth, within the sample of children, the magnitude of the effects increased as a function of reading ability, again supporting the Lexical Tuning Hypothesis. Overall, these data suggests that both the rate of lexical processing, and the flexibility of letter position encoding, increase with age and with reading skill. 


\section{Acknowledgements}

Ascensión Pagán was supported by a Vice Chancellor's Scholarship from the University of

Southampton.Hazel I. Blythe and Simon P. Liversedge were supported by the Leverhulme Trust (F/00180/AN). 


\section{References}

Acha, J. \& Perea, M. (2008). The effects of length and transposed letter similarity in lexical decision: Evidence with beginning, intermediate, and adult readers. British Journal of Psychology, 99(2), 245-264. doi: 10.1348/000712607X224478.

Ashby, J., Rayner, K., \& Clifton, C. (2005). Eye movements of highly skilled and average readers: Differential effects of frequency and predictability. The Quarterly Journal of Experimental Psychology Section A, 58(6), 1065-1086.

Ashby, J., Yang, J., Evans, K. H., \& Rayner, K. (2012). Eye movements and the perceptual span in silent and oral reading. Attention, Perception, \& Psychophysics, 74(4), 634-640.

Baayen, R. H., Davidson, D. J. \& Bates, D. M. (2008). Mixed-effects modeling with crossed random effects for subjects and items. Journal of Memory and Language, 59 (4), 390412. doi: http://dx.doi.org/10.1016/j.jml.2007.12.005.

Balota, D.A., Yap, M.J., Cortese, M.J., Hutchison, K.A., Kessler, B., Loftis, B., Neely, J.H., Nelson, D.L., Simpson, G.B., \& Treiman, R. (2007). The English Lexicon Project. Behavior Research Methods, 39, 445-459.

Barr, D. J., Levy, R., Scheepers, C., \& Tily, H. J. (2013). Random effects structure for confirmatory hypothesis testing: Keep it maximal. Journal of memory and language, $68(3), 255-278$.

Bates, D., Maechler, M., \& Bolker, B. (2012). Lme4: Linear mixed-effects models using S4 classes. R package version 0.999999-0. http://CRAN.project.org/package=lme4 .

Blythe, H. I. (2014). Developmental changes in eye movements and visual information encoding associated with learning to read. Current Directions in Psychological Science, 23(3), 201-207. 
Blythe, H. I. \& Joseph, H. (2011). Children's eye movements during reading. In S. P. Liversedge, I. D. Gilchrist, \& S. Everling (Eds.). Oxford Handbook on Eye Movements (pp. 643-662). Oxford: University Press.

Blythe, H. I., Johnson, R. L., Liversedge, S. P., \& Rayner, K. (2014). Reading transposed text: effects of transposed letter distance and consonant-vowel status on eye movements. Attention, Perception, \& Psychophysics, 76(8), 2424-2440.

Blythe, H. I., Häikiö, T., Bertam, R., Liversedge, S. P., \& Hyönä, J. (2011). Reading disappearing text: Why do children refixate words? Vision research, 51(1), 84-92.

Blythe, H. I., Liversedge, S. P., Joseph, H. S., White, S. J., \& Rayner, K. (2009). Visual information capture during fixations in reading for children and adults. Vision Research, 49(12), 1583-1591.

Blythe, H. I., Liversedge, S. P., Joseph, H. S., White, S. J., Findlay, J. M., \& Rayner, K. (2006). The binocular coordination of eye movements during reading in children and adults. Vision Research, 46(22), 3898-3908.

Briihl, D., \& Inhoff, A. W. (1995). Integrating information across fixations during reading: The use of orthographic bodies and of exterior letters. Journal of Experimental Psychology: Learning, Memory, and Cognition, 21(1), 55.

Castles, A., Davis, C. \& Forster, K.I. (2003). Word recognition development in children: Insights from masked priming. In Kinoshita. S. \& Lupker, S. (Eds.). Masked priming: State of the Art (pp. 345-360). London, UK: Psychology Press.

Castles, A., Davis, C., \& Letcher, T. (1999). Neighbourhood effects on masked form-priming in developing readers. Language and Cognitive processes, 14, 201-224.

Castles, A., Davis, C., Cavalot, P., \& Forster, K. (2007). Tracking the acquisition of orthographic skills in developing readers: Masked priming effects. Journal of 
Experimental Child Psychology, 97(3), 165-182. doi:

http://dx.doi.org/10.1016/j.jecp.2007.01.006.

Chace, K. H., Rayner, K., \& Well, A. D. (2005). Eye movements and phonological parafoveal preview: effects of reading skill. Canadian Journal of Experimental Psychology, 59(3), 209-217. doi: 10.1037/h0087476.

Davis, C. J. (1999). The self-organising lexical acquisition and recognition (SOLAR) model of visual word recognition. Dissertation Abstracts International: Section B: The Sciences and Engineering 62(1-B). Tesis doctoral no publicada, Universidad de New South Wales.

Davis, C. J. (2010). SOLAR versus SERIOL revisited. European Journal of Cognitive Psychology, 22, 695-724. doi:10.1080/09541440903155682.

Friedmann, N., Dotan, D., \& Rahamim, E. (2010). Is the visual analyzer orthographicspecific? Reading words and numbers in letter position dyslexia. Cortex, 46(8), 982-1004.

Frost, R. (2012). A universal approach to modeling visual word recognition and reading: Not only possible, but also inevitable. Behavioral and Brain Sciences, 35(05), 310-329.

Gagl, B., Hawelka, S., Richlan, F., Schuster, S., \& Hutzler, F. (2014). Parafoveal preprocessing in reading revisited: Evidence from a novel preview manipulation. Journal of Experimental Psychology: Learning, Memory, and Cognition, 40(2), 588.

Gómez, P., Ratcliff, R. \& Perea, M. (2008). The overlap model: A model of letter position coding. Psychological Review, 115, 577-601. doi:10.1037/a0012667.

Grainger, J. (2008). Cracking the orthographic code: An introduction. Language and Cognitive Processes, 23(1), 1-35. doi:10.1080/01690960701578013.

Grainger, I. J. \& Van Heuven, W. J. B. (2003). Modeling Letter Position Coding in Printed Word Perception. En P. Bonin (Ed.), Mental lexicon: "Some words to talk about words" (pp. 1-23). Hauppauge, NY: Nova Science. 
Grainger, J., \& Ziegler, J. C. (2011). A dual-route approach to orthographic processing. Frontiers in psychology, 2-54, doi: 10.3389/fpsyg.2011.00054.

Grainger, I. J., Granier, J. P., Farioli, F., Van Assche, E. \& Van Heuven, W. J. B. (2006). Letter position information and printed word perception: The relative-position priming constraint. Journal of Experimental Psychology: Human Perception and Performance, 32, 865-884. doi:10.1037/0096-1523.32.4.865.

Grainger, J., Lété, B., Bertand, D., Dufau, S., \& Ziegler, J. C. (2012). Evidence for multiple routes in learning to read. Cognition, 123(2), 280-292.

Haenggi, D., \& Perfetti, C. A. (1994). Processing components of college-level reading comprehension. Discourse Processes, 17(1), 83-104.

Häikiö, T., Bertram, R., Hyönä, J., \& Niemi, P. (2009). Development of the letter identity span in reading: Evidence from the eye movement moving window paradigm. Journal of Experimental Child Psychology, 102, 167-181. doi:10.1016/j.jecp.2008.04.002.

Häikiö, T., Bertram, R., \& Hyönä, J. (2010). Development of parafoveal processing within and across words in reading: Evidence from the boundary paradigm. The Quarterly Journal of Experimental Psychology, 63(10), 1982-1998.

Huestegge, L., Radach, R., Corbic, D., \& Huestegge, S. M. (2009). Oculomotor and linguistic determinants of reading development: A longitudinal study. Vision Research, 49(24), 2948-2959.

Jared, D., Levy, B. A., \& Rayner, K. (1999). The role of phonology in the activation of word meanings during reading: evidence from proofreading and eye movements. Journal of Experimental Psychology: General, 128(3), 219-264.

Johnson, R. L. (2007). The flexibility of letter coding: Nonadjacent letter transposition effects in the parafovea. In R. P. G. van Gompel, M. H. Fisher, W. S. Murray, \& R. L. Hill (Eds.). 
Eye movements: A window on mind and brain (pp. 425-440). Oxford, United Kingdom: Elsevier.

Johnson, R. L., \& Dunne, M. D. (2012). Parafoveal processing of transposed-letter words and nonwords: Evidence against parafoveal lexical activation. Journal of Experimental Psychology: Human Perception and Performance, 38(1), 191.

Johnson, R. L., \& Eisler, M. E. (2012). The importance of the first and last letter in words during sentence reading. Acta psychologica, 141(3), 336-351.

Johnson, R. L., Perea, M. \& Rayner, K. (2007). Transposed letter effects in Reading: evidence from eye movements and parafoveal preview. Journal of Experimental Psychology: Human Perception and Performance, 33, 209-229. doi:10.1037/00961523.33.1.209.

Jordan, T. R., Thomas, S. M., Patching, G. R., \& Scott-Brown, K. C. (2003). Assessing the importance of letter pairs in initial, exterior, and interior positions in reading. Journal of Experimental Psychology: Learning, Memory, and Cognition, 29(5), 883.

Joseph, H. S., Liversedge, S. P., Blythe, H. I., White, S. J., \& Rayner, K. (2009). Word length and landing position effects during reading in children and adults. Vision Research, 49(16), 2078-2086.

Kezilas, Y., McKague, M., Kohnen, S., Badcock, N. A., \& Castles, A. (2017). Disentangling the developmental trajectories of letter position and letter identity coding using masked priming. Journal of Experimental Psychology: Learning, Memory, and Cognition, 43(2), 250.

Kinoshita, S., Castles, A., \& Davis, C. (2009). The role of neighbourhood density in transposed-letter priming. Language and Cognitive Processes, 24(4), 506-526.

Kohnen, S., \& Castles, A. (2013). Pirates at parties: letter position processing in developing readers. Journal of experimental child psychology, 115(1), 91-107. 
Kohnen, S., Nickels, L., Castles, A., Friedmann, N., \& McArthur, G. (2012). When 'slime' becomes 'smile': developmental letter position dyslexia in English. Neuropsychologia, 50(14), 3681-3692.

Kuperman, V., Stadthagen-Gonzalez, H., \& Brysbaert, M. (2012). Age-of-acquisition ratings for 30,000 English words. Behavior Research Methods, 44(4), 978-990.

Lété, B., \& Fayol, M. (2013). Substituted-letter and transposed-letter effects in a masked priming paradigm with French developing readers and dyslexics. Journal of experimental child psychology, 114(1), 47-62.

Liversedge, S. P., \& Findlay, J. M. (2000). Eye movements reflect cognitive processes. Trends in Cognitive Sciences, 4, 6-14.

Luke, S. G., Henderson, J. M., \& Ferreira, F. (2015). Children's eye-movements during reading reflect the quality of lexical representations: An individual differences approach. Journal of Experimental Psychology: Learning, Memory, and Cognition. In press.

Mancheva, L., Reichle, E.D., Lemaire, B., Valdois, S., Ecalle, J. \& Guérin-Dugué (2015). An analysis of reading skill development using E-Z Reader. Journal of Cognitive Psychology, 27(5), 657-676.

Masterson, J., Stuart, M., Dixon, M., Lovejoy, D., \& Lovejoy, S. (2003). The children's printed word database.

McConkie, G. W., Zola, D., Grimes, J., Kerr, P. W., Bryant, N. R., \& Wolff, P. M. (1991). Children's eye movements during reading. Vision and visual dyslexia, 13.

Pagán, A., Blythe, H. I., \& Liversedge, S. P. (2016). Parafoveal pre-processing of word initial trigrams during reading in adults and children. Journal of Experimental Psychology: Learning, Memory and Cognition, 42 (3),411- 432. 
Paterson, K.B., Read, J., McGowan, V. A. \& Jordan, T. R. (2015). Children and adults both see 'pirates' in 'parties': letter-position effects for developing readers and skilled adults readers. Developmental Science, 18 (2), 335-343. Doi: 10.1111/desc.12222.

Perea, M., \& Estévez, A. (2008). Transposed-letter similarity effects in naming pseudowords: Evidence from children and adults. European Journal of Cognitive Psychology, 20(1), 3346. doi: 10.1080/09541440701306941.

Perea, M. \& Lupker, S. J. (2003). Does jugde activate COURT? Transposed-letter similarity effects in masked associative priming. Memory and Cognition, 31, 829-841. doi:10.1080/09541440701306941.

Perea, M. \& Lupker, S. J. (2004). Can CANISO activate CASINO? Transposed-letter similarity effects with nonadjacent letter positions. Journal of Memory and Language, 51(2), 231-246. doi:10.1016/j.jml.2004.05.005.

Perea, M., \& Lupker, S. J. (2007). La posición de las letras externas en el reconocimiento visual de palabras. Psicothema, 19, 559-564.

Perfetti, C.A, \& Hart, L. (2001). The lexical bases of comprehension skill. In D. Gorfien (Ed.), On the consequences of meaning selection (pp. 67-86). Washington, DC: American Psychological Association.

Perfetti, C.A., \& Hart, L. (2002). The lexical quality hypothesis. In L. Vehoeven. C. Elbro, \& P. Reitsma (Eds.), Precursors of functional literacy (pp. 189-213). Amsterdam/Philadelphia: John Benjamins.

Plummer, P., \& Rayner, K. (2012). Effects of parafoveal word length and orthographic features on initial fixation landing positions in reading. Attention, Perception, \& Psychophysics, 74(5), 950-963.

R Core Team. R (2013). A language and environment for statistical computing, R foundation for statistical computing. Vienna, Austria. http://www.R-project.org/ 
Rayner, K. (1975). The perceptual span and peripheral cues in reading. Cognitive Psychology, 7(1), 65-81.)

Rayner, K. (1986). Eye movements and the perceptual span in beginning and skilled readers. Journal of Experimental Child Psychology, 41, 211-236.

Rayner, K. (2009). The Thirty-Five Sir Frederick Bartlett Lecture: Eye movement and attention during reading, scene perception and visual search. Quarterly Journal of Experimental Psychology, 62, 1457-1506.

Rayner, K. \& Kaiser, J. S. (1975). Reading mutilated text. Journal of Educational Psychology, 67, 301-306.

Rayner, K., McConkie, G. W., \& Zola, D. (1980). Integrating information across eye movements. Cognitive Psychology, 12(2), 206-226.

Rayner, K., White, S. J., Johnson, R. L. \& Liversedge, S. P. (2006). Raeding wrods with jubmled letters: There's a cost. Psychological Science, 17, 192-193.

Reichle, E. D., Liversedge, S. P., Drieghe, D., Blythe, H. I., Joseph, H. S., White, S. J., \& Rayner, K. (2013). Using EZ Reader to examine the concurrent development of eyemovement control and reading skill. Developmental Review, 33(2), 110-149.

Tiffin-Richards, S.P. \& Schroeder, S. (2015). Children's and adults' parafoveal processes in German: Phonological and orthographic effects. Journal of Cognitive Psychology, 27(5), 531-548. Doi: 10.1080/20445911.2014.999076.

Veldre, A., \& Andrews, S. (2014). Lexical quality and eye movements: Individual differences in the perceptual span of skilled adult readers. The Quarterly Journal of Experimental Psychology, 67(4), 703-727.

Veldre, A., \& Andrews, S. (2015a). Parafoveal preview benefit is modulated by the precision of skilled readers' lexical representations. Journal of Experimental Psychology: Human Perception and Performance, 41(1), 219. 
Veldre, A., \& Andrews, S. (2015b). Parafoveal lexical activation depends on skilled reading proficiency. Journal of Experimental Psychology: Learning, Memory, and Cognition, $41(2), 586$.

Wang, H. C., Schotter, E. R., Angele, B., Yang, J., Simovici, D., Pomplun, M., \& Rayner, K. (2013). Using singular value decomposition to investigate degraded Chinese character recognition: evidence from eye movements during reading. Journal of research in reading, 36(S1), $\mathrm{S} 35-\mathrm{S} 50$.

Wechsler (2005). Wechsler Individual Achievement Test (WIAT-II UK). Harcourt Assessment.

Whitney, C. (2001). How the brain encodes the order of letters in a printed word: The SERIOL model and selective literature review. Psychonomic Bulletin and Review, 8, 221243. doi:10.3758/BF03196158.

White, S., \& Liversedge, S. (2004). Orthographic familiarity influences initial eye fixation positions in reading. European Journal of Cognitive Psychology, 16 (1-2), 52-78.

White, S. J., \& Liversedge, S. P. (2006). Foveal processing difficulty does not modulate nonfoveal orthographic influences on fixation positions. Vision Research, 46(3), 426-437.

White, S. J., Johnson, R. L., Liversedge, S. P., \& Rayner, K. (2008). Eye movements when reading transposed text: The importance of word beginning letters. Journal of Experimental Psychology: Human Perception and Performance, 34, 1261-1276.

Yan, G., Bai, X., Zang, C., Bian, Q., Cui, L., Qi, W., ... \& Liversedge, S. P. (2012). Using stroke removal to investigate Chinese character identification during reading: Evidence from eye movements. Reading and Writing, 25(5), 951-979.

Zang, C., Liang, F., Bai, X., Yan, G., \& Liversedge, S. P. (2013). Interword spacing and landing position effects during Chinese reading in children and adults. Journal of 
Experimental Psychology: Human Perception and Performance, 39(3), 720 -734. doi: 10.1037/a0030097.

Ziegler, J. C., Bertrand, D., Lété, B., \& Grainger, J. (2014). Orthographic and phonological contributions to reading development: Tracking developmental trajectories using masked priming. Developmental psychology, 50(4), 1026. 
Figure 1. Linear regression line on log-transformed reading times on control sentences as a function of children's reading ability (centered), using the plot function in R. Grey areas reflect the interval of confidence.

a) Average Fixation Duration (Log-Transformed)

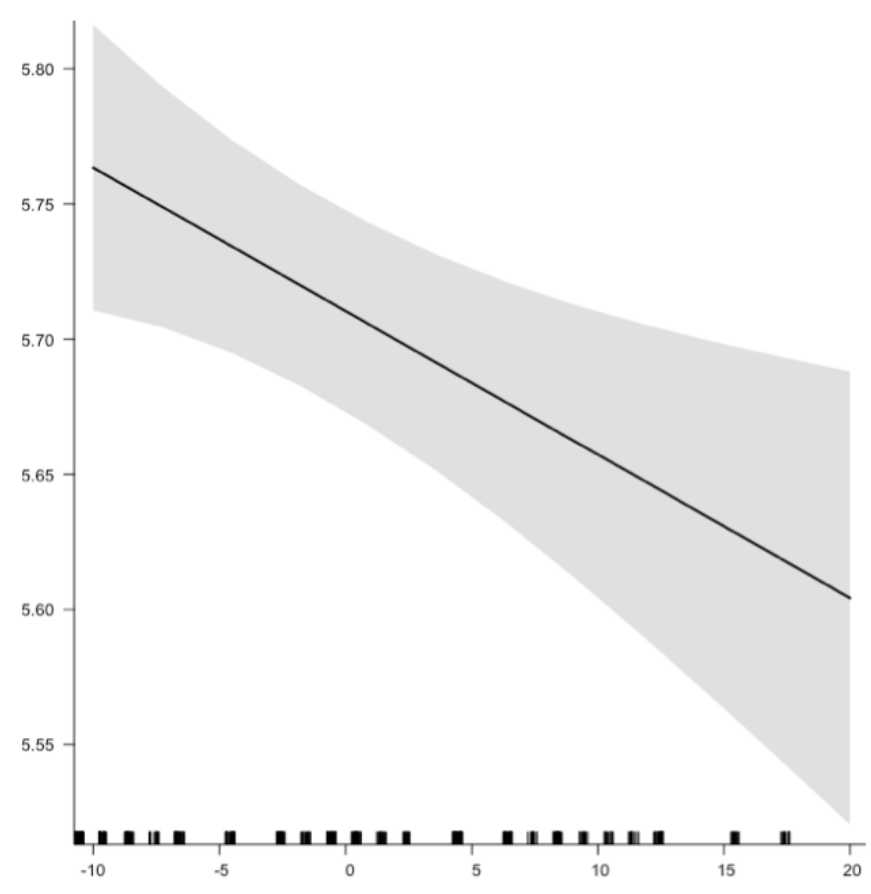

Reading Ability-Centered

(WIAT-II) b) Total Sentence Reading Times (Log-Transformed)

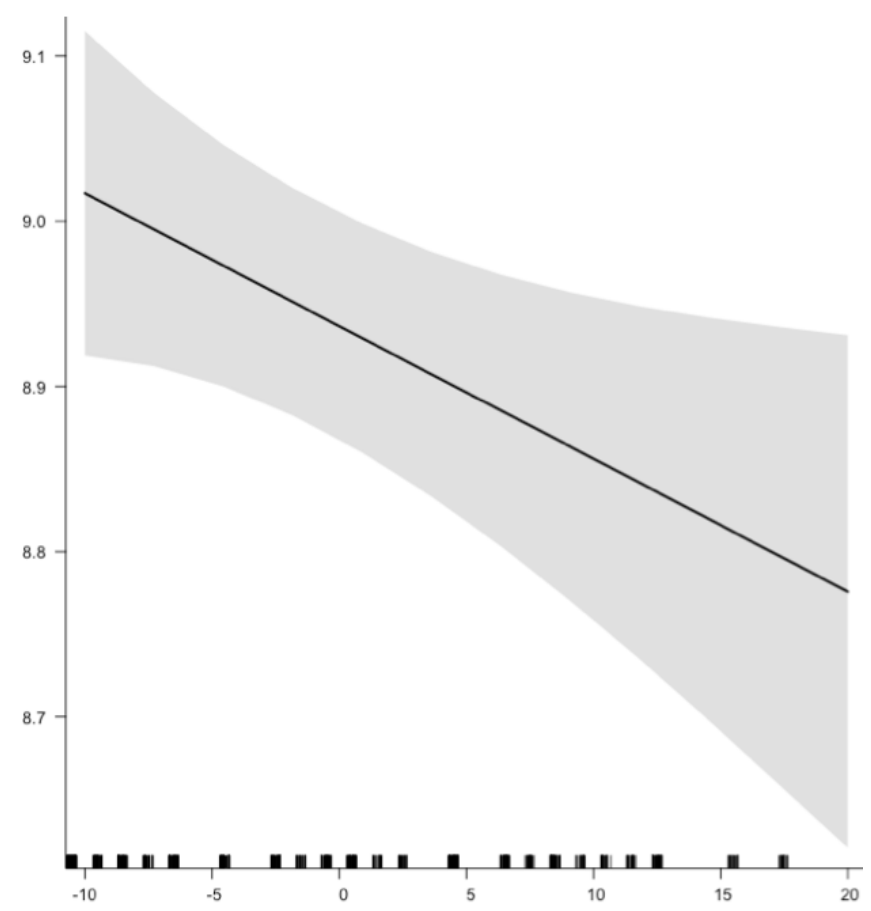

Reading Ability-Centered (WIAT-II) 

Figure 2. Mean and standard errors (error bars) on the four types of word/nonwords for adults and children in first fixation, gaze duration, go past time and total time.

First Fixation Duration

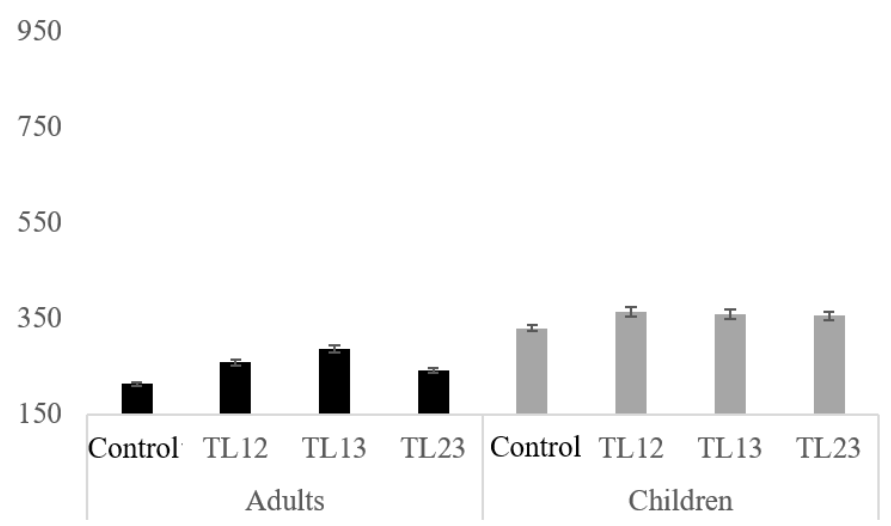

Go Past Time

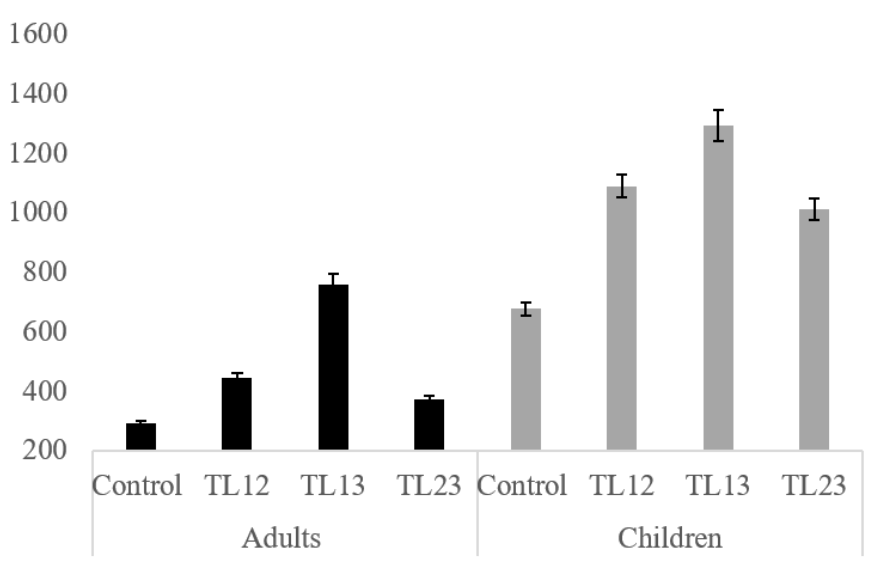

Gaze Duration

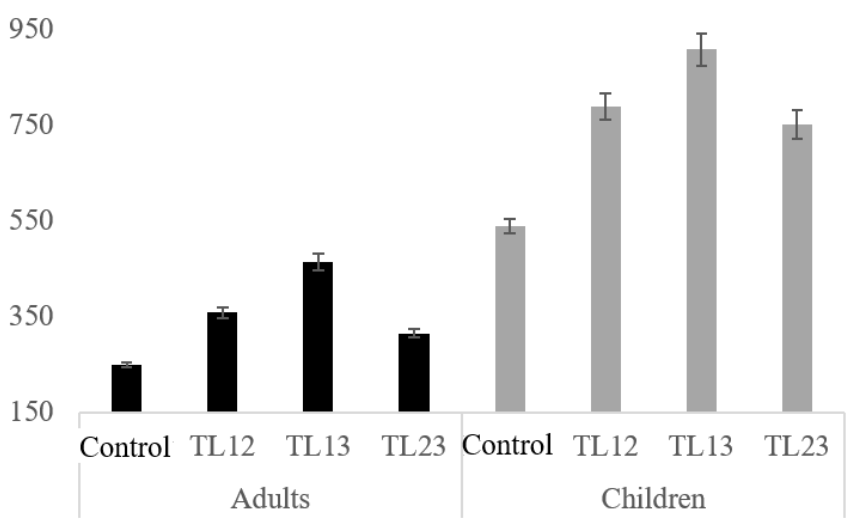

$$
\text { Total Time }
$$

1600

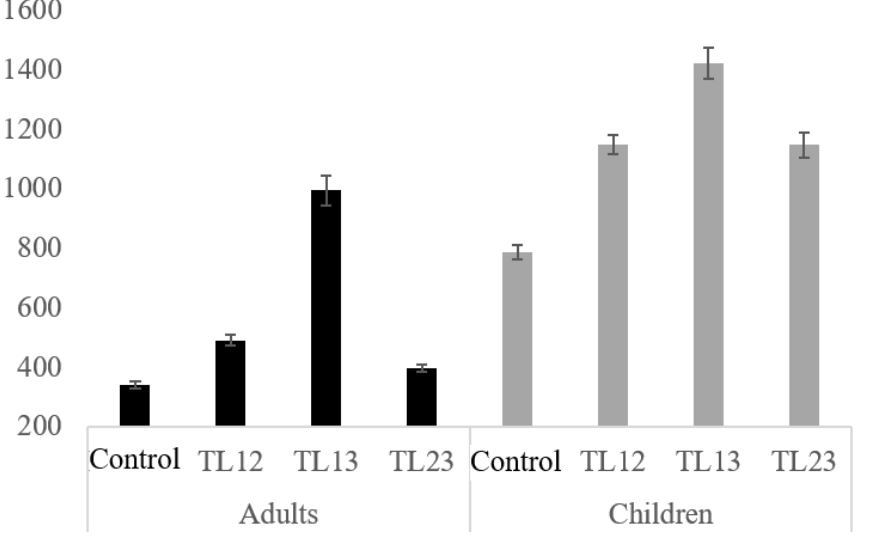



Figure 3. Linear regression lines for log-transformed total times on the four types of word/nonwords (black line- control, red line-TL12, green line-TL13 and blue line-TL23 as a function of children's reading ability (centered).

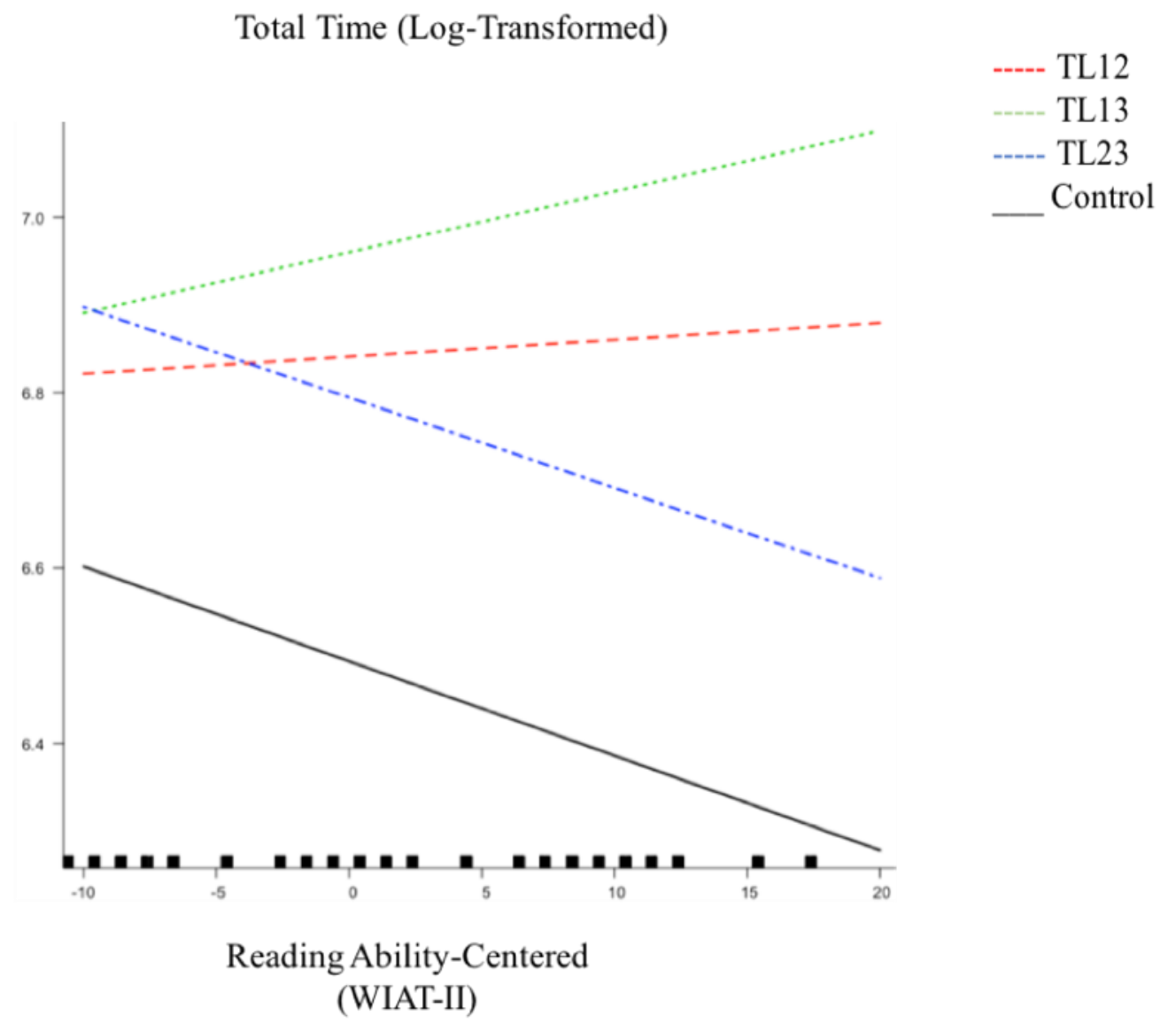



Table 1. Descriptive measures (maximum (max), minimum (min), median, mean and standard deviation (sd) for both comprehension and target questions in the eye tracker experiment, and the different subtest assessed with the WIAT-II (row and standardized scores) for both adults and children.

\begin{tabular}{|c|c|c|c|c|c|c|c|c|c|c|}
\hline & \multicolumn{5}{|c|}{ Adults } & \multicolumn{5}{|c|}{ Children } \\
\hline & $\max$ & $\min$ & median & mean & $\mathrm{sd}$ & $\max$ & $\min$ & median & mean & $\mathrm{sd}$ \\
\hline \multicolumn{11}{|l|}{ Eye tracker experiment } \\
\hline Comprehension Questions (\%) & 100 & 82 & 100 & 97 & 4 & 100 & 65 & 86 & 83 & 9 \\
\hline Target Questions (\%) & 100 & 100 & 100 & 100 & 0 & 100 & 71 & 100 & 97 & 6 \\
\hline \multicolumn{11}{|l|}{ WIAT-II } \\
\hline Age & 27 & 18 & 19 & 20 & 2 & 10 & 8 & 9 & 9 & 1 \\
\hline Word Reading (131-Acc) & 131 & 123 & 129 & 128 & 2 & 118 & 84 & 104 & 102 & 8 \\
\hline Word Reading Standardized & 121 & 96 & 114 & 113 & 5 & 127 & 85 & 106 & 104 & 10 \\
\hline Pseudoword Decoding (55-Acc) & 55 & 50 & 53 & 52 & 1 & 53 & 27 & 45 & 44 & 6 \\
\hline Pseudoword Dec. Standardized & 122 & 106 & 114 & 112 & 5 & 122 & 92 & 112 & 110 & 7 \\
\hline Comprehension (60-Acc) & 56 & 38 & 45 & 45 & 5 & 50 & 24 & 36 & 36 & 7 \\
\hline Comprehension Standardized & 121 & 103 & 114 & 113 & 5 & 123 & 88 & 102 & 103 & 9 \\
\hline Composite & 352 & 320 & 340 & 338 & 10 & 369 & 275 & 319 & 317 & 22 \\
\hline Composite Standardized & 131 & 107 & 119 & 119 & 7 & 132 & 89 & 105 & 105 & 10 \\
\hline Reading Speed (s) & 573 & 139 & 352 & 337 & 86 & 354 & 113 & 197 & 203 & 58 \\
\hline
\end{tabular}



Table 2. Descriptive Means (Standard Deviations) for each participant group in each dependent measure on the correctly spelled sentence.

\begin{tabular}{lcccc}
\hline & Fixation & Saccade & Sentence reading & Total \\
& Duration (ms.) & Amplitude (deg.) & time (ms.) & fumber of \\
& & & & \\
& $229(41)$ & $1.7(0.7)$ & $4296(1102)$ & $11.3(3.7)$ \\
Adults & $306(53)$ & $1.3(0.6)$ & $8068(2904)$ & $18.7(6.8)$ \\
\hline
\end{tabular}


Table 3. Descriptive Means (Standard Deviations) for each participant group in each dependent measure on the target word.

\begin{tabular}{|c|c|c|c|c|c|}
\hline $\begin{array}{l}\text { First Fixation } \\
\text { Duration }\end{array}$ & $\begin{array}{c}\text { Single } \\
\text { Fixation } \\
\text { Duration }\end{array}$ & $\begin{array}{c}\text { Gaze } \\
\text { Duration }\end{array}$ & Go Past Time & Total Time & $\begin{array}{c}\text { Total } \\
\text { Fixation } \\
\text { Count }\left(1^{\text {st }} \text { pass }\right)\end{array}$ \\
\hline
\end{tabular}

\begin{tabular}{|c|c|c|c|c|c|c|c|}
\hline & Control & $213(68)$ & $223(78)$ & $249(98)$ & 290 (179) & $340(214)$ & $1.5(0.8)$ \\
\hline \multirow{3}{*}{ Adults } & TL12 & 258 (118) & 284 (137) & 358 (206) & 444 (328) & $490(310)$ & $1.8(1.0)$ \\
\hline & TL13 & $287(148)$ & 339 (172) & $463(317)$ & 759 (569) & 994 (905) & $3.2(2.7)$ \\
\hline & TL23 & $242(86)$ & 263 (109) & 315 (157) & $373(223)$ & 397 (235) & $1.6(0.8)$ \\
\hline \multirow{4}{*}{ Children } & Control & $330(151)$ & $393(165)$ & $538(351)$ & $677(532)$ & $786(544)$ & $2.5(1.6)$ \\
\hline & TL12 & $363(223)$ & $467(235)$ & $789(620)$ & 1089 (887) & 1148 (774) & $3.2(2.1)$ \\
\hline & TL13 & 359 (207) & 468 (194) & $908(762)$ & $1293(1171)$ & $1422(1212)$ & $3.8(2.8)$ \\
\hline & TL23 & 356 (196) & 421 (187) & $752(674)$ & $1011(846)$ & 1147 (988) & $3.2(2.3)$ \\
\hline \multirow{3}{*}{ Adults } & TL12 & $21 \%$ & $27 \%$ & $44 \%$ & $53 \%$ & $44 \%$ & $44 \%$ \\
\hline & TL13 & $35 \%$ & $52 \%$ & $86 \%$ & $162 \%$ & $86 \%$ & $192 \%$ \\
\hline & TL23 & $14 \%$ & $18 \%$ & $27 \%$ & $29 \%$ & $27 \%$ & $17 \%$ \\
\hline \multirow{3}{*}{ Children } & TL12 & $10 \%$ & $19 \%$ & $47 \%$ & $61 \%$ & $47 \%$ & $46 \%$ \\
\hline & TL13 & $9 \%$ & $19 \%$ & $69 \%$ & $91 \%$ & $69 \%$ & $81 \%$ \\
\hline & TL23 & $8 \%$ & $7 \%$ & $40 \%$ & $50 \%$ & $40 \%$ & $46 \%$ \\
\hline
\end{tabular}


Table 4. Lme model (Group*Type); with extra planned contrasts for all the dependent measures in the target word.

\begin{tabular}{|c|c|c|c|c|c|c|c|c|c|c|c|c|c|c|c|c|c|c|}
\hline & \multicolumn{3}{|c|}{$\begin{array}{c}\text { Single Fixation } \\
\text { Duration }\end{array}$} & \multicolumn{3}{|c|}{$\begin{array}{c}\text { First Fixation } \\
\text { Duration }\end{array}$} & \multicolumn{3}{|c|}{ Gaze Duration } & \multicolumn{3}{|c|}{ Go Past Time } & \multicolumn{3}{|c|}{ Total Time } & \multicolumn{3}{|c|}{$\begin{array}{c}\text { Total Number } \\
\text { Fixations } \\
\end{array}$} \\
\hline & $\mathrm{b}$ & $\mathrm{SE}$ & $\mathrm{t}$ & $\mathrm{b}$ & SE & $\mathrm{t}$ & $\mathrm{b}$ & $\mathrm{SE}$ & $\mathrm{t}$ & $\mathrm{b}$ & $\mathrm{SE}$ & $\mathrm{t}$ & $\mathrm{b}$ & $\mathrm{SE}$ & $\mathrm{t}$ & $\mathrm{b}$ & $\mathrm{SE}$ & $\mathrm{t}$ \\
\hline Intercept (grand mean) & 5.78 & 0.03 & 206.5 & 5.58 & 0.02 & 263.3 & 6.01 & 0.04 & 158.02 & 6.25 & 0.05 & $\begin{array}{c}135.4 \\
0\end{array}$ & 6.38 & 0.05 & 139.6 & 0.72 & 0.04 & 19.6 \\
\hline Children-Adults & 0.44 & 0.05 & 9.03 & 0.29 & 0.04 & 7.08 & 0.65 & 0.06 & 10.34 & 0.73 & 0.07 & 10.5 & 0.71 & 0.07 & 9.83 & 0.39 & 0.06 & 6.46 \\
\hline TL12- Control & 0.18 & 0.03 & 5.35 & 0.09 & 0.022 & 4.21 & 0.29 & 0.03 & 9.75 & 0.37 & 0.03 & 12.12 & 0.35 & 0.03 & 11.53 & 0.18 & 0.03 & 6.35 \\
\hline TL13-TL12 & 0.1 & 0.04 & 2.64 & 0.04 & 0.02 & 1.89 & 0.15 & 0.03 & 5.01 & 0.27 & 0.03 & 8.60 & 0.35 & 0.03 & 11.6 & 0.27 & 0.03 & 9.65 \\
\hline TL23-TL13 & -0.15 & 0.04 & -4.05 & -0.05 & 0.02 & -2.34 & -0.21 & 0.03 & -7.32 & -0.35 & 0.03 & -11.53 & -0.45 & 0.03 & -15.08 & -0.33 & 0.03 & -11.75 \\
\hline Child-Adul:TL12-Control & -0.09 & 0.07 & -1.35 & -0.12 & 0.04 & -2.68 & -0.02 & 0.06 & -0.43 & 0.05 & 0.06 & 0.88 & 0.00 & 0.06 & -0.05 & 0.02 & 0.06 & 0.38 \\
\hline Child-Adul:TL13-TL12 & -0.15 & 0.08 & -1.93 & -0.08 & 0.04 & -1.88 & -0.1 & 0.06 & -1.76 & -0.30 & 0.06 & -4.93 & -0.44 & 0.06 & -7.41 & -0.31 & 0.06 & -5.45 \\
\hline Child-Adul:TL23-TL13 & 0.15 & 0.08 & 1.94 & 0.13 & 0.04 & 2.84 & 0.15 & 0.06 & 2.54 & 0.33 & 0.06 & 5.49 & 0.58 & 0.06 & 9.75 & 0.41 & 0.06 & 7.27 \\
\hline \multicolumn{19}{|l|}{ Extra contrasts } \\
\hline Control-TL13 & -0.27 & 0.05 & -5.5 & 0.11 & 0.03 & -4.24 & -0.4 & 0.03 & -11.09 & -0.63 & 0.04 & -16.77 & -0.74 & 0.04 & -20.36 & -0.53 & 0.03 & -15.33 \\
\hline Control-TL23 & -0.02 & 0.05 & -0.41 & -0.04 & 0.03 & -1.34 & -0.07 & 0.04 & -1.76 & -0.02 & 0.04 & -0.48 & 0.1 & 0.04 & 2.47 & 0.15 & 0.04 & 3.82 \\
\hline TL12-TL23 & 0.06 & 0.04 & 1.46 & 0.03 & 0.03 & 1.14 & 0.1 & 0.08 & 2.89 & 0.10 & 0.04 & 2.58 & 0.05 & 0.04 & 1.38 & -0.01 & 0.03 & -0.44 \\
\hline Adul-Child:Control-TL13 & 0.27 & 0.1 & 2.74 & 0.21 & 0.05 & 3.8 & 0.19 & 0.07 & 2.65 & 0.44 & 0.07 & 5.9 & 0.74 & 0.07 & 10.06 & 0.5 & 0.07 & 7.29 \\
\hline Adul-Child:Control-TL23 & -0.06 & 0.1 & -0.61 & -0.01 & 0.06 & -0.1 & -0.12 & 0.08 & -1.48 & -0.39 & 0.09 & -4.49 & -0.58 & 0.08 & -6.84 & -0.43 & 0.08 & -5.4 \\
\hline Adul-Child:TL12-TL23 & 0.03 & 0.09 & 0.34 & -0.04 & 0.05 & -0.73 & 0.02 & 0.07 & 0.22 & 0.16 & 0.07 & 2.15 & 0.15 & 0.07 & 2.06 & 0.11 & 0.07 & 1.61 \\
\hline
\end{tabular}


Table 5. Lme model (Reading Ability (RA)*Type); with extra planned contrasts for all the dependent measures in the target word for the children sample.

\begin{tabular}{|c|c|c|c|c|c|c|c|c|c|c|c|c|c|c|c|c|c|c|}
\hline & \multicolumn{3}{|c|}{$\begin{array}{l}\text { Single Fixation } \\
\text { Duration }\end{array}$} & \multicolumn{3}{|c|}{$\begin{array}{c}\text { First Fixation } \\
\text { Duration }\end{array}$} & \multicolumn{3}{|c|}{ Gaze Duration } & \multicolumn{3}{|c|}{ Go Past Time } & \multicolumn{3}{|c|}{ Total Time } & \multicolumn{3}{|c|}{ Total Number Fixations } \\
\hline & $\mathrm{b}$ & SE & $\mathrm{t}$ & $\mathrm{b}$ & SE & $\mathrm{t}$ & $\mathrm{b}$ & SE & $\mathrm{t}$ & $\mathrm{b}$ & SE & $\mathrm{t}$ & $\mathrm{b}$ & SE & $\mathrm{t}$ & $\mathrm{b}$ & SE & $\mathrm{t}$ \\
\hline (Intercept) & 6.66 & 0.33 & 20.01 & 5.93 & 0.28 & 20.92 & 7.11 & 0.44 & 15.97 & 6.35 & 0.06 & 98.08 & 7.04 & 0.51 & 13.81 & 0.92 & 0.47 & 1.97 \\
\hline TL12- Control & -0.39 & 0.56 & -0.71 & -0.45 & 0.33 & -1.37 & -0.10 & 0.43 & -0.25 & 0.41 & 0.04 & 10.12 & -1.02 & 0.42 & -2.44 & -0.83 & 0.39 & -2.01 \\
\hline TL13-TL12 & -0.32 & 0.6 & -0.54 & 0.11 & 0.33 & 0.34 & -0.17 & 0.44 & -0.39 & 0.51 & 0.04 & 12.63 & -0.38 & 0.43 & -0.88 & -0.32 & 0.41 & -0.78 \\
\hline TL23-TL13 & 0.34 & 0.63 & 0.54 & 0.10 & 0.33 & -0.31 & 0.98 & 0.44 & 2.24 & 0.33 & 0.04 & 8.21 & 1.65 & 0.42 & 3.93 & 1.43 & 0.40 & 3.56 \\
\hline RA & -0.01 & 0.00 & -2.04 & 0.00 & 0.00 & -0.72 & -0.01 & 0.00 & -1.76 & -0.01 & 0.00 & -2.37 & 0.00 & 0.00 & -0.59 & 0.00 & 0.00 & 0.00 \\
\hline TL12-Control:RA & 0.00 & 0.00 & 0.95 & 0.00 & 0.00 & 1.48 & 0.00 & 0.00 & 0.88 & 0.01 & 0.00 & 2.91 & 0.01 & 0.00 & 3.27 & 0.00 & 0.00 & 2.57 \\
\hline TL13-TL12:RA & 0.00 & 0.01 & 0.59 & 0.00 & 0.00 & -0.34 & 0.00 & 0.00 & 0.61 & 0.02 & 0.00 & 4.46 & 0.00 & 0.00 & 1.18 & 0.00 & 0.00 & 1.07 \\
\hline TL23-TL13:RA & 0.00 & 0.01 & -0.68 & 0.00 & 0.00 & -0.27 & -0.01 & 0.00 & -2.57 & 0.00 & 0.00 & 0.31 & -0.02 & 0.00 & -4.32 & 0.01 & 0.00 & 3.90 \\
\hline \multicolumn{19}{|l|}{ Extra contrasts } \\
\hline Control-TL13 & 0.69 & 0.74 & 0.93 & 0.16 & 0.4 & 0.4 & 0.72 & 0.54 & 1.34 & -0.39 & 0.05 & -7.91 & 1.72 & 0.52 & 3.29 & 0.14 & 0.49 & 2.93 \\
\hline Control-TL23 & 0.05 & 0.83 & 0.06 & 0.34 & 0.46 & 0.75 & -0.88 & 0.62 & -1.42 & -0.23 & 0.06 & -3.99 & -0.63 & 0.59 & -1.06 & -0.61 & 0.57 & -1.07 \\
\hline TL12-TL23 & -0.04 & 0.72 & -0.06 & -0.38 & 0.4 & -0.95 & -0.37 & 0.54 & -0.68 & 0.19 & 0.05 & 3.89 & -0.96 & 0.52 & -1.83 & -0.81 & 0.50 & -1.63 \\
\hline Control-TL13:RA & -0.01 & 0.01 & -1.11 & 0.00 & 0.00 & -0.43 & -0.01 & 0.05 & -1.91 & -0.02 & 0.00 & -4.06 & -0.02 & 0.00 & -4.03 & -0.02 & 0.00 & -3.51 \\
\hline Control-TL23:RA & 0.00 & 0.01 & -0.12 & 0.00 & 0.00 & -0.85 & 0.01 & 0.06 & 1.21 & 0.00 & 0.01 & 0.87 & 0.00 & 0.00 & 0.76 & 0.00 & 0.00 & 0.97 \\
\hline TL12-TL23:RA & 0.00 & 0.01 & 0.16 & 0.00 & 0.00 & 0.98 & 0.00 & 0.05 & 0.89 & 0.01 & 0.00 & 1.59 & 0.00 & 0.00 & 2.08 & 0.01 & 0.00 & 1.72 \\
\hline
\end{tabular}




\section{Appendix}

Experimental sentences (correctly spelled words) and the three misspelled nonwords (TL12, TL13, TL23):

The blonde girl spotted the brown monkey in the zoo. (omnkey, nomkey, mnokey)

Tom got an appointment with the nice doctor in the hospital. (odctor, codtor, dcotor)

Peter put clothes in the laundry basket ready for washing. (absket, sabket, bsaket)

Paul and his friends go to the sports $\underline{\text { centre twice a week. (ecntre, nectre, cnetre) }}$

You can find nice fruit in the local market on Tuesdays. (amrket, ramket, mraket)

The men followed the rules of the young captain on the ship. (acptain, pactain, cpatain)

Kelly always chooses her lucky number to play the lottery. (unmber, munber, nmuber)

The man was in grave danger as he climbed the mountain. (adnger, nadger, dnager)

We saw a large badger when we went for a walk last night. (abdger, dabger, bdager)

We did not stay much longer than you at the birthday party. (olnger, nolger, lnoger)

Alex helped the animal rescue centre with his pocket money. (erscue, sercue, rsecue)

The teacher only found one small mistake in my homework. (imstake, simtake, msitake)

My sister saw the kind dentist today so she was not scared. (edntist, nedtist, dnetist)

A pet dog or cat can be great company for older people. (ocmpany, mocpany, company)

I like the grey donkey that lives in a field behind my house. (odnkey, nodkey, dnokey)

The singer became very nervous after making a mistake. (enrvous, renvous, nrevous)

Lisa was allowed to feed the young dolphin at the zoo. (odlphin, lodphin, dlophin)

I saw a film about a tiny little penguin on the tv today. (epnguin, nepguin, pneguin)

Daniel drew a picture with a green pencil for his grandma. (epncil, nepcil, pnecil)

Mum put a small candle on a cupcake for dad's birthday. (acndle, nacdle, cnadle)

My ears were sore after the really loud concert last night. (ocncert, noccert, cnocert)

My aunt Mary is the most distant relative in my family. (idstan, sidtant, dsitant)

The girl put in her contact lenses to go out with her friends. (elnses, nelses, lneses)

The letter was stuck with a large magnet on our fridge door. (amgnet, gamnet, mganet)

My uncle has a short temper and shouts when I'm naughty. (etmper, metper, tmeper) 
James got a special mention in assembly on his birthday. (emntion, nemtion, mnetion) Sue got her hair cut shorter than normal and it looked nice. (onrmal, ronmal, nromal) My family always goes on a long camping trip every summer. (acmping, macping, cmaping)

In winter we have central heating to keep our house warm. (ecntral, nectral, cnetral)

There is a huge temple in the city where people go to pray. (etmple, metple, tmeple)

The baby felt asleep after many tender kisses from his mum. (etnder, netder, tneder)

I found a little reptile hiding under a stone in our garden. (erptile, pertile, rpetile)

The clothes that people wore last century look really funny. (ecntury, nectury, cnetury)

I put lots of silver tinsel on the Christmas tree this year. (itnsel, nitsel, tnisel)

I made a lovely pie with pastry and apples this afternoon. (apstry, saptry, psatry)

Kate's clothes were in an awful tangle on the bedroom floor. (atngle, natgle, tnagle)

The boys all had spicy mustard with their burgers today. (umstard, sumtard, msutard)

I woke up and heard the clear tinkle of a bell somewhere. (itnkle, nitkle, tnikle)

The nurse had to put a fresh bandage on his leg after three weeks. (abndage, nabdage, bnadage)

The oil was stored in a huge tanker until it was needed. (atnker, natker, tnaker)

Beth went to the cinema to see the latest vampire film. (avmpire, mavpire, vmapire)

My football team's mascot is a giant teddy bear in uniform. (amscot, samcot, msacot)

The little boy is a real rascal because he plays jokes on people. (arscal, sacral, rsacal)

My neighbours planted a small conker tree in their garden. (ocnker, nocker, cnoker)

The potter had very nimble hands and made a lovely vase. (inmble, minble, nmible)

I heard the wind blowing through the tall bamboo plants. (abmboo, mabboo, bmaboo)

The new building has window ledges that are painted blue. (eldges, delges, ldeges)

Tom cried when his little finger got caught in the door. (ifnger, nifger, fniger)

I was given a plain biscuit but I prefer chocolate ones. (ibscuit, sibcuit, bsicuit)

Mum poured lots of yellow custard on my pudding at tea time. (ucstard, suctard, csutard)

The horse jumped six white fences and won the competition. (efnces, nefces, fneces)

We went to buy meat from the nice butcher across the street. (ubtcher, tubcher, btucher) 
The secretary left a thick bundle of letters on the table. (ubndle, nubdle, bnudle)

The ambulance took the hurt victim quickly to the hospital. (ivctim, civtim, vcitim)

The front bumper fell off dad's car today and he was cross. (ubmper, mubper, bmuper)

The boss bought a new dumper truck for the building project. (udmper, mudper, dmuper) 
${ }^{\mathrm{i}}$ They found a robust transposed letter effect for internal letter compared to initial letters in single, first fixations and gaze durations. Children, however, showed transposed letter effects for both initial and internal letter but only in single fixation duration. Tiffin-Richards and Schroeder note that their transposed letter effects in children should be “interpreted with caution" given that beginning readers make relatively few fixations when reading. 